\title{
Annuity Market Imperfection, Retirement and Economic Growth
}

\author{
BEN J. HEIJDRA \\ JOCHEN O. MIERAU
}

\begin{abstract}
CESIFO WORKING PAPER NO. 2717
Category 6: Fiscal Policy, Macroeconomics and Growth JULY 2009
\end{abstract}
An electronic version of the paper may be downloaded
- from the SSRN website: www.SSRN.com
- from the RePEc website: - from the CESifo website:




\title{
Annuity Market Imperfection, Retirement and Economic Growth
}

\begin{abstract}
We study the effects of an annuity market imperfection on individual agents' labour supply and retirement decisions and on the macroeconomic growth rate in an overlapping generations model with endogenous growth. We model imperfect annuities by introducing a load factor on the interest rate faced by finitely-lived agents. Our core model features age-independent wages and a constant mortality rate. In the first extension we study the implications for microeconomic decisions and macroeconomic outcomes of a hump-shaped life-cycle profile in labour productivity, whilst in the second extension we postulate a realistic mortality process. Our main findings are that the limited availability of annuities induces agents to retire early in the first two models, but later in the model with age-dependent mortality. In all cases, the general equilibrium repercussion is that economic growth is lower under imperfect annuities than with perfect annuities.
\end{abstract}

JEL Code: D52, D91, E10, J20.

Keywords: annuity markets, retirement, endogenous growth, overlapping generations, demography.

Ben J. Heijdra

Faculty of Economics and Business

University of Groningen

P.O. Box 800

9700 AV Groningen

The Netherlands

info@heijdra.org
Jochen O. Mierau

Faculty of Economics and Business

University of Groningen

P.O. Box 800

9700 AV Groningen

The Netherlands

j.o.mierau@rug.nl

July 13, 2009 


\section{Introduction}

Economic wisdom suggests that annuities are welfare maximizing in the presence of life-time uncertainty (Yaari, 1965). Surprisingly, however, the availability of annuities around the world is severely limited (Cannon and Tonks, 2008). Taking this observation into account, numerous studies have investigated the implications of the limited availability of annuities on life-cycle choices made by individuals (see, for instance, Abel, 1985, Hurd, 1989, and Leung, 1994, 2007).

The limited availability of annuities does not only affect decisions of individuals. Indeed, this financial imperfection also has aggregate effects on the economy through the market for loanable funds and the labour market. Somewhat surprisingly, however, this macroeconomic effect of imperfect annuity markets has only received scant attention in the literature. In the current paper we elaborate on exactly this point. That is, we study the implications of an imperfect annuity market on both the consumption, labour supply, retirement, and saving decisions by individual agents and the general equilibrium repercussions thereof.

We study the relationship between the annuity market imperfection and economic growth by developing an overlapping generations model featuring endogenous growth. Individuals choose labour supply endogenously. We model the annuity market imperfection by introducing a load factor which renders the interest rate on annuities less than actuarially fair. As a result, this load factor leads to profits for the annuity firms, which are redistributed to the agents in a lump-sum fashion. In the core model agents face a constant mortality rate (as in Blanchard, 1985) and constant productivity over their life-cycle. Although convenient to analyze, the core model suffers from a number of empirical deficiencies that might bias our results. To address these deficiencies we study two extensions, namely age-dependent productivity and mortality. We do so in isolation at first, and then in concert.

Our main finding is that an imperfect annuity market leads to a reduction of the economic growth rate, although the quantitative effect is rather small in a plausibly calibrated version of the model. This conclusion derives from the fact that overpriced annuities retard the accumulation of capital, which constitutes the engine of growth in our model. Furthermore, we find that incorporating realistic aspects of the life-cycle has important effects on the quantitative results. That is, whereas the core model suggests that a modest increase in the load factor causes a reduction in the growth rate of 28 basis points (from $1 \%$ per annum 
to $0.72 \%$ ), a plausibly calibrated model-featuring both extensions mentioned above-only suggests a reduction of about 9 basis points. This discrepancy is a direct consequence of the fact that the constant mortality rate featuring in the core model kills off the young too quickly and the old too slowly.

In addition we find that labour supply and-especially-retirement, are hardly affected by an imperfect annuity market. In the calibrated model, the increase in the load factor causes agents to retire 2 months later and to supply only marginally less labour during their active career. Again we find that a correctly modeled mortality structure is crucial. That is, in the core model agents retire 18 months early and reduce labour supply by $10 \%$ during their active career.

From a theoretical point of view two findings stand out. First, we find that, in the presence of annuity market imperfections and with age-dependent mortality, consumption exhibits a hump-shaped profile whereas for perfect annuities it is ever increasing. This is in line with the results of Bütler (2001) and Hansen and İmrohoroğlu (2008) who show that such imperfections lead the agents to discount future consumption by their mortality rate. Second, we find that asset accumulation decreases in the presence of an imperfect annuity market. A similar result is provided by Abel (1985) and Fuster (1999) who show that asset accumulation decreases if the elasticity of intertemporal substitution is not less than unity and there is steady state growth.

Previous work on the limited availability of annuities has mainly focused on individual choices, disregarding labour supply decisions and assuming the complete absence of annuity markets; see, for instance, Abel (1985), Hurd (1989), and Leung (1994, 2007). Similarly, the small number of computable general equilibrium (CGE) analyses have typically focused on the complete absence of annuities and exogenous labour supply; see, for instance, Fuster (1999), Conesa and Krueger (2006) and Conesa et al. (2009). In contrast, Pecchenino and Pollard (1997) use a Diamond-Samuelson model to study the general equilibrium impact of a truly imperfect annuity market. Although only focusing on individual choices, Bütler (2001) introduces endogenous labour supply and also focuses on an imperfect annuity market. Hansen and İmrohoroğlu (2008) drop the endogenous labour supply part of the Bütler (2001) model and study the implications of an imperfect annuity market in general equilibrium. Our paper adds to this literature by specifically focusing on imperfect annuities in relationship to 
endogenous labour supply and, especially, a realistic demographic structure. ${ }^{1}$

The remainder of the paper is structured as follows. Section 2 sets out the core model, whilst section 3 studies the relationship between annuity market imperfection, retirement and economic growth. Section 4 introduces the two extensions that allow our model to better resemble realistic features of life-cycle choices. Section 5 concludes. There is a separate appendix (Heijdra and Mierau, 2009a) containing all derivations.

\section{Model}

\section{$2.1 \quad$ Firms}

The production side of the model makes use of the insights of Romer (1989) and postulates the existence of sufficiently strong external effects operating between private firms in the economy. There is a large and fixed number, $N_{0}$, of identical, perfectly competitive firms. The technology available to firm $i$ is given by:

$$
Y_{i}(t)=Z(t) K_{i}(t)^{\varepsilon_{K}} L_{i}(t)^{1-\varepsilon_{K}}, \quad 0<\varepsilon_{K}<1,
$$

where $Y_{i}(t)$ is output, $K_{i}(t)$ is capital use, $L_{i}(t)$ is the labour input, and $Z(t)$ represents the general level of factor productivity which is taken as given by individual firms. The competitive firm hires factors of production according to the following marginal productivity conditions:

$$
\begin{aligned}
w(t) & =\left(1-\varepsilon_{K}\right) Z(t) \kappa_{i}(t)^{\varepsilon_{K}}, \\
r(t)+\delta & =\varepsilon_{K} Z(t) \kappa_{i}(t)^{\varepsilon_{K}-1},
\end{aligned}
$$

where $\kappa_{i}(t) \equiv K_{i}(t) / L_{i}(t)$ is the capital intensity. The rental rate on each factor is the same for all firms, i.e. they all choose the same capital intensity and $\kappa_{i}(t)=\kappa(t)$ for all $i=1, \cdots, N_{0}$. This is a very useful property of the model because it enables us to aggregate the microeconomic relations to the macroeconomic level.

Generalizing the insights of Saint-Paul (1992, p. 1247) and Paul Romer (1989) to a growing population, we assume that the inter-firm externality takes the following form:

$$
Z(t)=Z_{0} \kappa(t)^{1-\varepsilon_{K}},
$$

\footnotetext{
${ }^{1}$ Recent papers including a realistic demographic structure and perfect annuities in a general equilibrium setting include Boucekkine et al. (2002), d'Albis (2007), and Heijdra and Romp (2008, 2009a, 2009b).
} 
where $Z_{0}$ is a positive constant, $\kappa(t) \equiv K(t) / L(t)$ is the economy-wide capital intensity, $K(t) \equiv \sum_{i} K_{i}(t)$ is the aggregate capital stock, and $L(t) \equiv \sum_{i} L_{i}(t)$ is aggregate employment. According to (4), total factor productivity depends positively on the aggregate capital intensity, i.e. if an individual firm $i$ raises its capital intensity, then all firms in the economy benefit somewhat as a result because the general productivity indicator rises for all of them. Using (4), equations (1)-(3) can now be rewritten in aggregate terms: ${ }^{2}$

$$
\begin{aligned}
Y(t) & =Z_{0} K(t), \\
w(t) L(t) & =\left(1-\varepsilon_{K}\right) Y(t), \\
r(t) & =r=\varepsilon_{K} Z_{0}-\delta,
\end{aligned}
$$

where $Y(t) \equiv \sum_{i} Y_{i}(t)$ is aggregate output and we assume that capital is sufficiently productive, i.e. $\varepsilon_{K} Z_{0}-\delta>0$. The aggregate technology is linear in the capital stock and the interest is constant.

\subsection{Consumers}

\subsubsection{Individual behaviour}

We generalize the Blanchard (1985) model of consumer behaviour by including an endogenous labour-leisure decision and by assuming potentially imperfect annuity markets. At time $t$, expected remaining-lifetime utility of an individual born at time $v(v \leq t)$ is given by:

$$
E \Lambda(v, t) \equiv \int_{t}^{\infty} \ln \left[C(v, \tau)^{\varepsilon_{C}} \cdot[1-L(v, \tau)]^{\left(1-\varepsilon_{C}\right)}\right] \cdot e^{(\rho+\mu)(t-\tau)} d \tau,
$$

where $C(v, \tau)$ is consumption, $L(v, \tau)$ is labour supply (the time endowment is equal to unity), $\rho$ is the pure rate of time preference, and $\mu$ is the instantaneous mortality rate.

The agent's budget identity is given by:

$$
\dot{A}(v, \tau)=r^{A} A(v, \tau)+w(\tau) L(v, \tau)-C(v, \tau)+\Pi(v, \tau)
$$

where $A(v, \tau)$ is the stock of financial assets, $r^{A}$ is the annuity rate of interest rate, $w(\tau)$ is the wage rate, and $\Pi(v, \tau)$ is a lump-sum transfers from life insurance companies (see below).

\footnotetext{
${ }^{2}$ All firms use the same capital intensity $\left(\kappa_{i}(t)=\kappa(t)\right)$, so that $Y_{i}(t)=L_{i}(t) Z(t) \kappa(t)^{\varepsilon_{K}}$ and $Y(t)=L(t) Z(t) \kappa(t)^{\varepsilon_{K}}$. By using (4) in this expression, we find (5). For the wage we find $w(t)=$ $\left(1-\varepsilon_{K}\right) Z(t) \kappa(t)^{\varepsilon_{K}}=\left(1-\varepsilon_{K}\right) Z_{0} \kappa(t)$, which can be rewritten to get (6). Finally, for the rental rate on capital we find $r(t)+\delta=\varepsilon_{K} Z(t) \kappa(t)^{\varepsilon_{K}-1}=\varepsilon_{K} Z_{0}$.
} 
Following Yaari (1965), we postulate the existence of annuity markets, but unlike Yaari we allow the annuities to be less than actuarially fair. Since the agent is subject to lifetime uncertainty and has no bequest motive, he/she will fully annuitize so that the annuity rate of interest facing the agent is given by:

$$
r^{A} \equiv r+\theta \mu
$$

where $r$ is the real interest rate (see (7)), and $\theta$ is a load factor that measures the degree of imperfection of the annuities $(0 \leq \theta \leq 1)$. Although there are numerous explanations for the overpricing of annuities (Cannon and Tonks, 2008, ch. 8) the main reason for imperfections on the annuity markets seems to be adverse selection (Finkelstein and Poterba, 2002, 2004, and 2006). That is, agents with a low mortality rate are more likely to buy annuities than agents with high mortality rates. However, because mortality is private information annuity firms "mis-price" annuities for low-mortality agents, thus creating a load factor. ${ }^{3}$

Our specification is quite general and incorporates three important cases:

- Perfect annuities (PA). The case of perfect (actuarially fair) annuities is obtained by setting $\theta=1$. Life insurance companies break even, and $\Pi(v, \tau)=0$.

- Imperfect annuities (IA). The case of imperfect (less than actuarially fair) annuities is obtained by assuming $0<\theta<1$. Life insurance companies make excess profits, $\Pi(\tau)=\mu(1-\theta) A(\tau)$, which are taxed away by the government and distributed in a lump-sum fashion to surviving agents.

- No annuities (NA). For $\theta=0$ there are no annuity markets. The agent can save at the interest rate $r$, but borrowing is impossible because, with lifetime uncertainty, he/she faces a probabilistic time-of-death wealth constraint of the form, prob $\{A(v, \tau) \geq 0\}=1$ (Yaari, 1965, p. 139). By definition, $\Pi(v, \tau)=0$.

In the remainder of this paper we restrict attention to the PA and IA cases. ${ }^{4}$

The agent chooses time profiles for $C(v, \tau), A(v, \tau)$, and $L(v, \tau)$ (for $\tau \geq t$ ) in order to maximize (1), subject to (i) the budget identity (2), (ii) a NPG condition, $\lim _{\tau \rightarrow \infty} A(v, \tau)$

\footnotetext{
${ }^{3}$ Alternatively adverse selection effects could lead to quantity rationing in the sense that agents cannot buy the amount of annuities they want (see, Eckstein et al., 1985 and Eichenbaum and Peled, 1987). In the current paper we ignore such rationing and focus purely on the price effect of adverse selection.

${ }^{4}$ We study the NA case in a companion paper; see Heijdra and Mierau (2009b).
} 


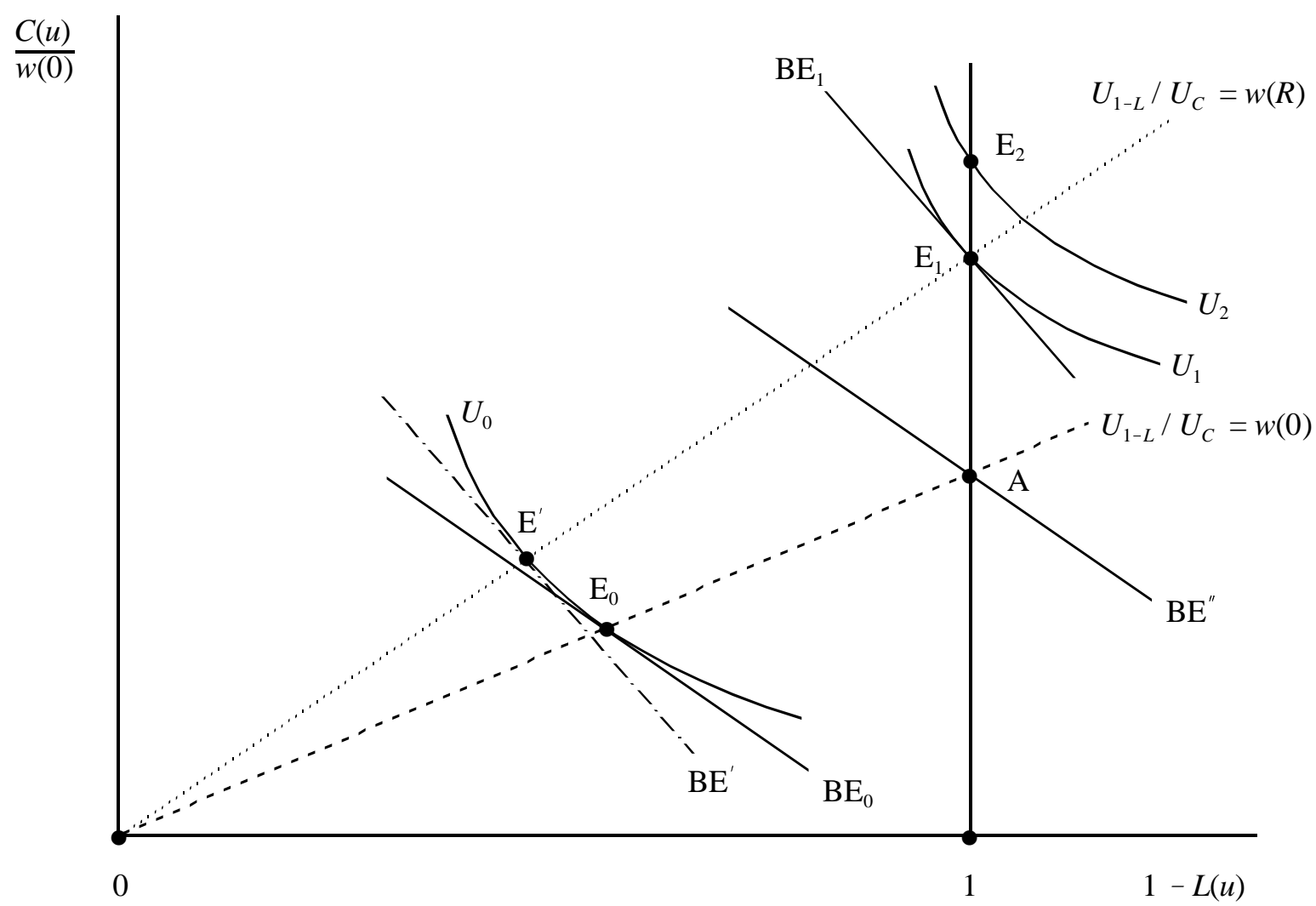

Figure 1: Life-cycle consumption, labour supply, and retirement

$e^{(r+\theta \mu)(t-\tau)}=0$, (iii) the initial asset position in the planning period, $A(v, t)$, and (iv) a non-negativity condition, $L(v, \tau) \geq 0$. The solution of this optimization problem is presented in detail in Heijdra and Mierau (2009a, Appendix A). For expositional purposes, however, here we restrict attention to the optimal individual life-cycle decisions in the context of an economy moving along a steady-state balanced growth path. ${ }^{5}$

Along the balanced growth path, labour productivity grows at a constant exponential rate, $\hat{\gamma}$ (see below), and as a result individual agents face an upward sloping path for real wages over their lifetimes:

$$
w(\tau)=w(v) e^{\hat{\gamma}(\tau-v)} .
$$

The consumption Euler equation is given by:

$$
\frac{\dot{C}(v, \tau)}{C(v, \tau)}=r-\rho-(1-\theta) \mu>0 .
$$

\footnotetext{
${ }^{5}$ The transitional dynamic properties of the models discussed in this paper can be studied numerically by discretizing it.
} 
With imperfect annuities, individual consumption growth is affected by the mortality rate, a result first demonstrated for the case with $\theta=0$ by Yaari (1965, p. 143). During the working period, the agent equates the marginal rate of substitution between leisure and consumption to the wage rate at all times, i.e.:

$$
\frac{\left(1-\varepsilon_{C}\right) /(1-L(v, \tau))}{\varepsilon_{C} / C(v, \tau)}=w(\tau) .
$$

The consumption-leisure choice is illustrated in Figure 1, where $C(u) / w(0)$ and $L(u)$ stand for, respectively, consumption (scaled by the wage rate at birth) and labour supply of the agent at age $u$. The initial choice at age $u=0$ is at point $\mathrm{E}_{0}$ where there is a tangency between an indifference curve (labeled $U_{0}$ ) and a "budget line" (labeled $\left.\mathrm{BE}_{0}\right){ }^{6}$ If there were no economic growth, the wage rate would be constant over the agent's lifetime and the optimum would gradually move along the dashed line from $\mathrm{E}_{0}$ to $\mathrm{A}$ at which point it is optimal to retire. This move reflects the positive wealth effect on the demands for consumption and leisure. After retirement, the agent would move along the vertical leisure constraint in the direction of points $\mathrm{E}_{1}$ and $\mathrm{E}_{2}$.

Matters are slightly more complicated in the presence of economic growth and an upward sloping wage profile (11). Over the agent's life the utility-expansion path rotates in a counterclockwise fashion inducing substitution effects. In terms of Figure 1, the agent retires at point $\mathrm{E}_{1}$ where the marginal rate of substitution between leisure and consumption is equal to $w(R)$, where $R$ stands for this agent's age at retirement. Using the dotted utility-expansion line through point $\mathrm{E}_{1}$ we find that the total effect on consumption and leisure during working life is given by the move from $\mathrm{E}_{0}$ to $\mathrm{E}_{1}$. The pure substitution effect is given by the move from $\mathrm{E}_{0}$ to $\mathrm{E}^{\prime}$, and the wealth effect is the move from $\mathrm{E}^{\prime}$ to $\mathrm{E}_{1}$.

Armed with this graphical apparatus we can deduce the following analytical expressions. Consumption of a newborn is given by:

$$
C(v, v)=\frac{\varepsilon_{C}(\rho+\mu)}{\varepsilon_{C}+\left(1-\varepsilon_{C}\right)\left[1-e^{-(\rho+\mu) R(v)}\right]} \cdot L I(v, v),
$$

where $R(v)$ is the retirement age chosen by an agent born at time $v$, and $L I(v, v)$ is lifetime

\footnotetext{
${ }^{6}$ During the working period, the budget line is given by:

$$
X(v, \tau)=w(\tau)[1-L(v, \tau)]+C(v, \tau)
$$

where $X(v, \tau)$ is full consumption. The line $\mathrm{BE}_{0}$ is obtained by subsituting $X(v, v)$.
} 
income of the agent:

$$
L I(v, v)=w(v) \cdot \frac{1-e^{-(r-\hat{\gamma}+\theta \mu) R(v)}}{r-\hat{\gamma}+\theta \mu}+L T(v, v),
$$

where $L T(v, v)$ are lifetime transfers received from the government:

$$
L T(v, v) \equiv \int_{v}^{\infty} \Pi(v, \tau) e^{(r+\theta \mu)(v-\tau)} d \tau .
$$

Equation (14) shows that consumption of a newborn is proportional to lifetime income. The marginal propensity to consume out of lifetime income is decreasing in the retirement age. Equation (15) provides the definition of lifetime income. The first term on the right-hand side represents the present value of the time endowment during working life, using the growthcorrected annuity rate of interest $(r-\hat{\gamma}+\theta \mu)$ for discounting. The later one retires, the higher is this term. The second term on the right-hand side of (15) is just the present value of transfers, defined in (16).

Point $\mathrm{E}_{1}$ in Figure 1 is attained at the point where consumption satisfies:

$$
C(v, v+R(v))=\frac{\varepsilon_{C}}{1-\varepsilon_{C}} w(v) e^{\hat{\gamma} R(v)} .
$$

By using (12) we find that $C(v, \tau)=C(v, v) e^{(r-\rho-(1-\theta) \mu)(\tau-v)}$ so that (17) can be rewritten as:

$$
\frac{C(v, v)}{w(v)}=\frac{\varepsilon_{C}}{1-\varepsilon_{C}} e^{-(r-\hat{\gamma}-\rho-(1-\theta) \mu) R(v)} .
$$

Equations (14) (with (15) substituted), and (18) represent a simultaneous system implicitly determining $C(v, v) / w(v)$ and $R(v)$ as a function of the structural parameters $\left(\varepsilon_{C}, \rho, \mu, r\right.$, and $\theta)$, the macroeconomic growth rate $(\hat{\gamma})$, and relative lifetime transfers $(L T(v, v) / w(v))$.

We illustrate the optimal retirement choice in Figure 2. This figure is based on the following parameter settings. The interest rate is set at six percent per annum $(r=0.06)$ whilst the rate of time preference is three and a half percent $(\rho=0.035)$. These values imply that in the presence of perfect annuities, individual consumption grows at 2.5 percent per annum (see (12)). The instantaneous mortality rate is estimated with Dutch mortality data for the cohort born in 1960 (see below for details). This yields a value of 1.26 percent per annum $(\mu=0.0126)$, implying an expected remaining lifetime of 79.4 years. We assume that labour productivity growth equals one percent per annum $(\hat{\gamma}=0.01)$, and set the utility parameter for consumption at such a value that the optimal retirement age with perfect 


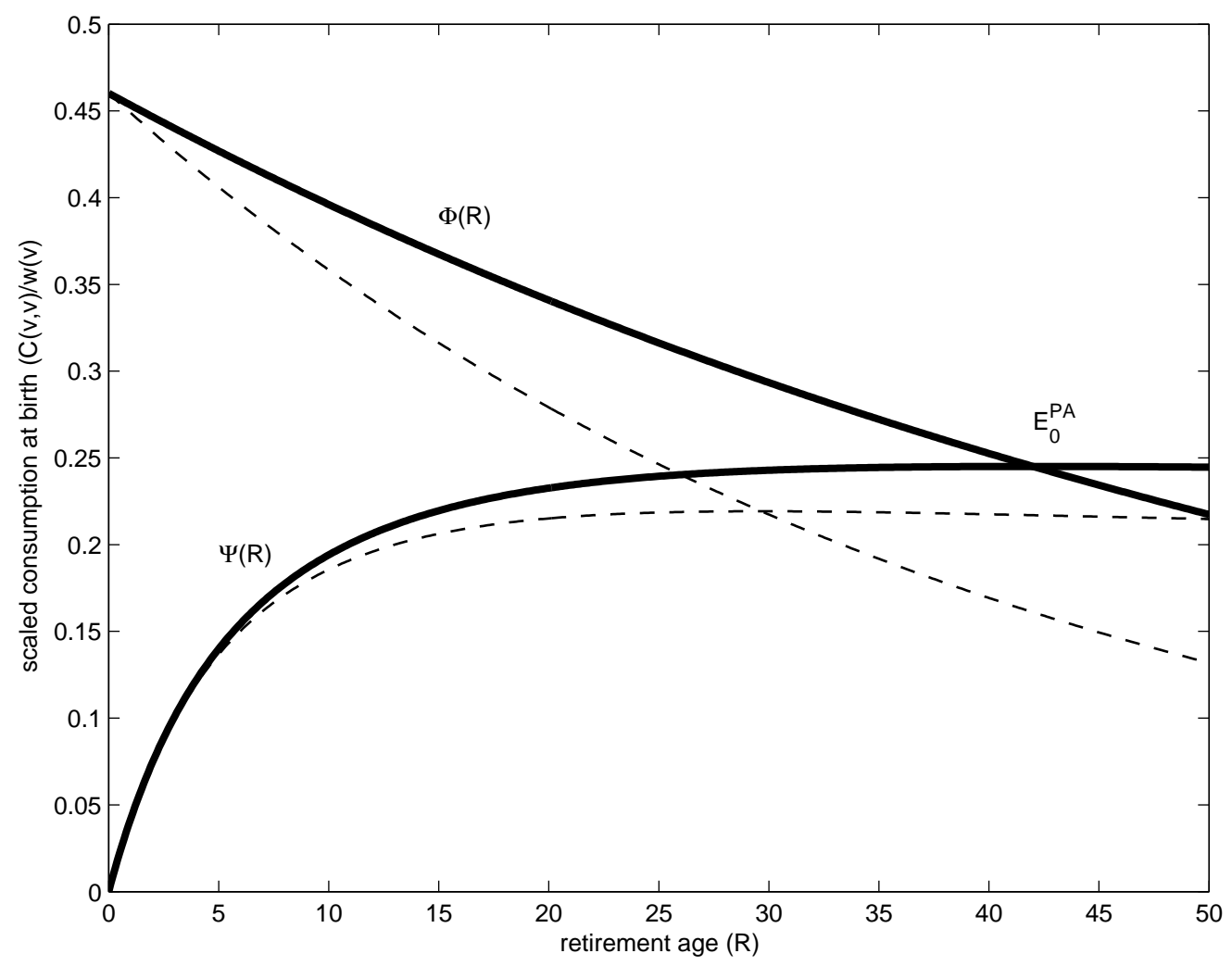

Figure 2: Optimal retirement age

annuities is $R^{*}=42$ years. This yields a value of $\varepsilon_{C}=0.3152$. Finally, we assume that annuities are perfect, i.e. $\theta=1$ in Figure 2. This simplifies matters somewhat because $L T(v, v)=0$ for this case.

In Figure 2, the $\Psi(R)$ function plots the combinations between $C(v, v) / w(v)$ and $R(v)$ implied by equations (14)-(15) (with $L T(v, v)=0$ imposed). Despite the fact that the marginal propensity to consume is a downward sloping function of the retirement age, lifetime income is sharply increasing in the retirement age and $\Psi(R)$ is upward sloping as a result. The downward sloping $\Phi(R)$ function plots equation (18) and intersects $\Psi(R)$ at point $\mathrm{E}_{0}^{P A}$. There is a unique optimal retirement age which, for the parameters used here, equals $R^{*}=42$.

Figure 2 also illustrates the partial equilibrium effects of a change in the macroeconomic growth rate, $\hat{\gamma}$. Indeed, the thin dashed lines depict the $\Phi(R)$ and $\Psi(R)$ functions for the zero-growth case $(\hat{\gamma}=0)$, for which the optimal retirement age is $R^{*}=29.7$ years. In 
terms of Figure 1, this is the case where the agent moves from $\mathrm{E}_{0}$ to $\mathrm{A}$ along the dashed utility-expansion curve. With a flat wage profile, equilibrium consumption at birth (and at all ages) and the retirement age are both lower than with an upward sloping wage profile. Finally, we note that an increase in lifetime transfers leads to an upward shift in $\Psi(R)$, higher consumption at birth and a lower retirement age. The transfers thus cause a negative wealth effect on the optimal retirement age.

With imperfect annuities $(0<\theta<1)$ we must confront the issue of redistribution of excess profits and recognize the fact that $L T(v, v)$ will be positive in general. To keep things as simple as possible, we assume that the lump-sum transfers are set according to:

$$
\Pi(v, \tau)=z \cdot w(\tau)
$$

where $z$ is a positive indexing parameter, that is taken as given by individual agents but determined endogenously in general equilibrium via the balanced budget requirement of the redistribution scheme (see below). By using (19) in (16) we find:

$$
\frac{L T(v, v)}{w(v)} \equiv \frac{z}{r-\hat{\gamma}+\theta \mu} .
$$

We prove in Heijdra and Mierau (2009a, Appendix A) that $z$ is constant along the balanced growth path. ${ }^{7}$ Equations (14)-(15), (18), and (20) in combination imply that the retirement age is independent of $v$, i.e. $R(v)=R^{*}$ for all $v$. We summarize this important result in the following proposition.

Proposition 1 Consider lump-sum redistribution of excess profits of life-insurance companies, of the form $\Pi(v, \tau)=z \cdot w(\tau)$. In that case: (i) the retirement age is independent of $v$, i.e. $R(v)=R^{*}$ for all $v$; (ii) the ratio between consumption at birth and the wage rate at birth is independent of $v$, i.e. $C(v, v) / w(v)=\frac{\varepsilon_{C}}{1-\varepsilon_{C}} e^{-(r-\hat{\gamma}-\rho-(1-\theta) \mu) R^{*}}$ for all $v$.

\subsubsection{Aggregate household behaviour}

In this subsection we derive expressions for per-capita average consumption, saving, and labour supply. Following Buiter (1988), we allow for constant population growth $\pi$ and

\footnotetext{
${ }^{7}$ An alternative feasible redistribution scheme would set $\Pi(v, \tau)=z \cdot w(v)$, implying that $L T(v, v) / w(v)=$ $z /(r+\theta \mu)$ along the balanced growth path. Interestingly, "actuarially fair" lump-sum redistribution, setting transfers according to $\Pi(v, \tau)=\mu(1-\theta) A(v, \tau)$, is infeasible. Under such a scheme, $L T(v, v)$ becomes unbounded which is clearly infeasible.
} 
distinguish between the birth rate, $\beta$, and the mortality rate rate, $\mu$, so that $\pi \equiv \beta-\mu$. The relative cohort weights evolve according to:

$$
p(v, t) \equiv \frac{P(v, t)}{P(t)}=\beta e^{\beta(v-t)}, \quad t \geq v,
$$

where $P(v, t)$ is the size of cohort $v$ at time $t$ and $P(t)$ is the total population. Using (21), we can define per-capita average values in general terms as:

$$
x(t) \equiv \int_{-\infty}^{t} p(v, t) X(v, t) d v,
$$

where $X(v, t)$ denotes the variable in question at the individual level, and $x(t)$ is the per capita average value of the same variable.

Off the steady-state growth path, exact analytical aggregation of the individual behavioural decision rules is impossible. To see why this is the case, note, for example, that consumption of workers features an age-dependent propensity to consume out of age-dependent wealth making aggregation impossible. We therefore focus on steady-state relationships. We know that $R(v)=R^{*}$ for all $v$, so for consumption we find:

$$
\begin{aligned}
C(v, v) & =\frac{\varepsilon_{C}}{1-\varepsilon_{C}} w(v) e^{-[r-\hat{\gamma}-\rho-(1-\theta) \mu] R^{*}}, \\
C(v, t) & =C(v, v) e^{[r-\rho-(1-\theta) \mu](t-v)},
\end{aligned}
$$

whilst the wage rate satisfies equation (11). Using (22), per capita average consumption is thus given by:

$$
c(t) \equiv \int_{-\infty}^{t} p(v, t) C(v, t) d v \equiv \frac{C(v, v)}{w(v)} \cdot \frac{\beta w(t)}{\hat{\gamma}+\beta+\rho+(1-\theta) \mu-r} .
$$

It follows from (13) and (23)-(24) that labour supply of workers in period $t\left(t-v \leq R^{*}\right)$ can be written as:

$$
L(v, t)=1-e^{-[r-\hat{\gamma}-\rho-(1-\theta) \mu]\left(R^{*}+v-t\right)} .
$$

Since $L(v, t)=0$ for retirees $\left(t-v>R^{*}\right)$, per capita average labour supply is equal to:

$$
\begin{aligned}
l(t) & \equiv \int_{t-R^{*}}^{t} p(v, t) L(v, t) d v \\
& =\left[1-e^{-\beta R^{*}}\right]-\beta e^{-\beta R^{*}} \cdot \frac{e^{[\hat{\gamma}+\beta+\rho+(1-\theta) \mu-r] R^{*}}-1}{\hat{\gamma}+\beta+\rho+(1-\theta) \mu-r} \equiv l,
\end{aligned}
$$

with $0<l<1$. The term in square brackets on the right-hand of (27) provides the first mechanism by which $l$ falls short of unity: agents retire and their unit time endowment is 
consumed in full in the form of leisure. The second composite term on the right-hand side of (27) represents the second mechanism by which $l$ falls short of unity: as workers age they reduce their labour supply.

At the individual level, financial assets are accumulated according to:

$$
\dot{A}(v, t)=(r+\theta \mu) A(v, t)+w(t) L(v, t)+z w(v)-C(v, t),
$$

where $L(v, t)=0$ for retirees (for $t-v>R^{*}$ ). Per capita aggregate assets are defined as $a(t) \equiv \int_{-\infty}^{t} p(v, t) A(v, t) d v$ so that:

$$
\dot{a}(t)=\int_{-\infty}^{t} p(v, t) \dot{A}(v, t) d v-\beta a(t),
$$

where we have incorporated the fact that individual agents are born bare of financial assets $(A(v, v)=0)$ and that cohort shares evolve over time according to $\dot{p}(v, t)=-\beta p(v, t)$. Substituting (28) into (29) and noting (27) we obtain:

$$
\dot{a}(t)=(r+\theta \mu-\beta) a(t)+w(t) l(t)+z w(t)-c(t) .
$$

The balanced-budget requirement for the lump-sum redistribution scheme is given in per capita terms by:

$$
\mu(1-\theta) a(t)=z w(t) .
$$

Finally, by substituting (31) into (30) we obtain:

$$
\dot{a}(t)=(r+\mu-\beta) a(t)+w(t) l(t)-c(t) .
$$

Like in the standard case with perfect annuities, the aggregate per capita annuity receipts, $\theta \mu a(t)$, do not feature directly in (32) because they constitute pure transfers from the dead to the living. In each period, life insurance companies receive $\mu a(t)$ from the estates of the deceased and pay $\theta \mu a(t)$ to their surviving customers. The resulting profit, $(1-\theta) \mu a(t)$, is taxed away by the government and redistributed to the surviving agents. The transfers debudget from the per capita average asset accumulation equation.

\subsection{Balanced growth path}

In the absence of government bonds, the capital market equilibrium condition is given by $A(t)=K(t)$. In per capita average terms we thus find:

$$
a(t)=k(t),
$$


Table 1: Balanced growth and retirement in the core model

(a) Microeconomic relationships:

$$
\begin{aligned}
\frac{C(v, v)}{w(v)} & =\frac{\varepsilon_{C}(\rho+\mu)}{\varepsilon_{C}+\left(1-\varepsilon_{C}\right)\left[1-e^{\left.-(\rho+\mu) R^{*}\right]}\right.} \cdot \frac{1-e^{-(r-\hat{\gamma}+\theta \mu) R^{*}}+z}{r-\hat{\gamma}+\theta \mu} \\
\frac{C(v, v)}{w(v)} & =\frac{\varepsilon_{C}}{1-\varepsilon_{C}} e^{-(r-\hat{\gamma}-\rho-(1-\theta) \mu) R^{*}}
\end{aligned}
$$

(b) Macroeconomic relationships:

$$
\begin{aligned}
z & =\mu(1-\theta) \frac{k(t)}{w(t)} \\
\hat{\gamma} & \equiv \frac{\dot{k}(t)}{k(t)}=r-\pi+\left[l-\frac{c(t)}{w(t)}\right] \cdot \frac{w(t)}{k(t)} \\
\frac{w(t) l}{k(t)} & =\left(1-\varepsilon_{K}\right) Z_{0} \\
l & \equiv 1-e^{-\beta R^{*}}-\beta e^{-\beta R^{*}} \frac{e^{[\hat{\gamma}+\beta+\rho+(1-\theta) \mu-r] R^{*}}-1}{\hat{\gamma}+\beta+\rho+(1-\theta) \mu-r} \\
\frac{c(t)}{w(t)} & \equiv \frac{\beta(v, v)}{\hat{\gamma}+\beta+\rho+(1-\theta) \mu-r} \cdot \frac{C}{w(v)}
\end{aligned}
$$

Definitions: Endogenous are $C(v, v) / w(v), R^{*}, z, \hat{\gamma}, l, w(t) / k(t)$, and $c(t) / k(t)$. Parameters: birth rate $\beta$, mortality rate $\mu$, population growth rate $\pi \equiv \beta-\mu$, imperfection annuities $\theta$, rate of time preference $\rho$, capital coefficient in the technology $\varepsilon_{K}$, consumption coefficient in tastes $\varepsilon_{C}$, scale factor in the technology $Z_{0}$. The interest rate is $r \equiv \varepsilon_{K} Z_{0}-\delta$, where $\delta$ is the depreciation rate of capital. 
where $k(t) \equiv K(t) / P(t)$ is the per capita stock of capital. From (5)-(6) we easily find:

$$
\begin{aligned}
y(t) & =Z_{0} k(t), \\
w(t) l(t) & =\left(1-\varepsilon_{K}\right) y(t),
\end{aligned}
$$

where $y(t) \equiv Y(t) / P(t)$ is per capita output.

The macroeconomic growth model has been written in a compact format in Table 1. Equation (T1.1) is obtained by substituting (15) and (20) into (14). Equation (T1.2) is the same as (23). Equation (T1.3) is (31) with (33) substituted. Equation (T1.4) is obtained by substituting (33) into (32). Equation (T1.5) is obtained by combining (34)-(35) and noting (27). Equation (T1.6) is the same as (27). Finally, (T1.7) is the same as (25).

The model features a two-way interaction between the microeconomic decisions and the macroeconomic outcomes. Equations (T1.1)-(T1.2) determine scaled newborn consumption, $C(v, v) / w(v)$, and the optimal retirement age, $R^{*}$, as a function of the key macroeconomic variables. Equations (T1.3)-(T1.7) determine equilibrium transfers, $z$, the macroeconomic growth rate, $\hat{\gamma}$, the overall wage-capital ratio, $w(t) / k(t)$, aggregate labour supply, $l$, and the $c(t) / w(t)$ ratio as a function of the optimal retirement age and scaled newborn consumption.

\section{Retirement, growth and annuities}

In this section we compute and visualize the comparative static general equilibrium effects for the core model of Table 1 . To compute the initial general equilibrium we assume that annuities are perfect $(\theta=1)$ and use the coefficient values mentioned above (in the paragraph below equation (18)). We assume that rate of population growth is one percent per annum $(\pi=0.01)$. Since $\pi \equiv \beta-\mu$, this implies that, for the mortality rate that was postulated above, the birth rate is $\beta=0.0226$. The capital depreciation rate is ten percent per annum $(\delta=0.10)$. We use the efficiency parameter of capital as a calibration parameter and find $\varepsilon_{K}=0.9241 .{ }^{8}$ It follows that the constant in the production function is equal to $Z_{0}=(r+\delta) / \varepsilon_{K}=0.1731$. The initial steady-state growth path has the following features: $C(v, v) / w(v)=0.2451$, $R^{*}=42, z=0, \hat{\gamma}=0.01, l=0.1802, c(t) / w(t)=0.7286$, and $w(t) / k(t)=0.0729$. For

\footnotetext{
${ }^{8}$ This is, of course, an implausibly high value, signalling that it is hard to obtain a calibration for the core model that yields plausible values for all parameters. Below we introduce some model extensions that allow us to substantially improve the quality of the calibration in this respect.
} 
convenience these values are restated in the first column in Table 2(a).

Figure 3 visualizes some of the key features of the calibration. Figure 3(a) depicts the general equilibrium determination of the retirement age and the macroeconomic growth rate. The curve labeled MIE represents the microeconomic equilibrium condition, i.e. it depicts $\left(\hat{\gamma}, R^{*}\right)$ combinations for which (T1.1) and (T1.2) are equated (recall that $z=0$ in the base case, so the microeconomic equilibrium can be computed conditional on the macroeconomic growth rate only). In Figure 3(a), the line labeled MAE depicts the macroeconomic equilibrium conditions, i.e. it depicts $\left(\hat{\gamma}, R^{*}\right)$ combinations for which $(\mathrm{T} 1.3)-(\mathrm{T} 1.7)$ are satisfied. The equilibrium is at point $\mathrm{E}_{0}$, where MIE and MAE intersect.

Figure 3 also illustrates the steady-state age profiles for the key variables (solid lines). Figure $3(\mathrm{~b})$ shows that the logarithm of scaled consumption is linear is the agents age. Figure $3(\mathrm{c})$ shows that the agent gradually reduces the number of hours supplied to the labour market, and retires permanently at age $R^{*}=42$. Finally, Figure 3(d) shows that the path of financial assets is monotonically increasing in age, and features a slight kink at the retirement age.

Next we consider the equilibrium under imperfect annuities. Instead of setting $\theta=1$, we simulate the model with a value of $\theta=0.70$ and keep all other parameters the same. The new equilibrium values for the different variables are reported in the second column in Table 2(a). Obviously, with imperfect annuities lump-sum transfers become positive. Interestingly, agents reduce lifetime labour supply and retire about one and a half years earlier than under perfect annuities.

The new growth rate is about three quarters of its value under perfect annuities. In Figure 4 we visualize the general equilibrium effects of $\theta$ on the retirement decision and scaled consumption of a newborn. The solid lines depict the case with perfect annuities $(\theta=1)$. The equilibrium is at point $\mathrm{E}^{\mathrm{PA}}$. The thick dashed lines illustrate the case with imperfect annuities $(\theta=0.70)$, taking into account the general equilibrium effects on $\hat{\gamma}$ and $z$. The equilibrium with imperfect annuities is at point $\mathrm{E}^{\mathrm{IA}}$, which lies north-west of point $\mathrm{E}^{\mathrm{PA}}$. Agents retire earlier in life and consume more at birth. The thinly dashed line in Figure 4 depicts the $\Psi(R)$-line for imperfect annuities, but assuming that the transfers are zero. The total effect of the move from $\mathrm{E}^{\mathrm{PA}}$ to $\mathrm{E}^{\mathrm{IA}}$ can thus be decomposed into a part that is caused by the effect of the growth rate, and a part that is caused by lump-sum transfers. 
Table 2: Growth and retirement: quantitative effects

\begin{tabular}{|c|c|c|c|c|c|c|c|c|c|}
\hline \multirow[b]{3}{*}{$\frac{C(v, v)}{w(v)}$} & \multicolumn{2}{|c|}{ (a) Core case } & \multicolumn{2}{|c|}{ (b) Productivity } & \multicolumn{2}{|c|}{ (c) Mortality } & \multicolumn{3}{|c|}{ (d) Combined } \\
\hline & $\theta=1.0$ & $\theta=0.7$ & $\theta=1.0$ & $\theta=0.7$ & $\theta=1.0$ & $\theta=0.7$ & $\theta=1.0$ & $\begin{array}{l}\theta=0.7 \\
\text { (i) }\end{array}$ & (ii) \\
\hline & 0.2451 & 0.2606 & 0.1966 & 0.2065 & 0.2395 & 0.2421 & 0.2061 & 0.2067 & 0.1947 \\
\hline$S^{*}$ (years) & 0 & 0 & 2.06 & 2.52 & 0 & 0 & 2.06 & 2.10 & 1.61 \\
\hline$R^{*}$ (years) & 42 & 40.49 & 42 & 41.31 & 42 & 42.72 & 42 & 42.15 & 39.68 \\
\hline$z$ & 0 & 0.0465 & 0 & 0.0343 & 0 & 0.0115 & 0 & 0.0092 & 0 \\
\hline$\hat{\gamma}(\%)$ & 1.00 & 0.72 & 1.00 & 0.70 & 1.00 & 0.94 & 1.00 & 0.91 & 0.61 \\
\hline$l($ or $n)$ & 0.1802 & 0.1616 & 0.1862 & 0.1695 & 0.2162 & 0.2103 & 0.2385 & 0.2324 & 0.2284 \\
\hline$\frac{c(t)}{w(t)}$ & 0.7286 & 0.6881 & 0.5846 & 0.5596 & 0.3702 & 0.3623 & 0.3187 & 0.3123 & 0.3233 \\
\hline$\frac{w(t)}{k(t)}$ & 0.0729 & 0.0813 & 0.1004 & 0.1103 & 0.2597 & 0.2669 & 0.4990 & 0.5120 & 0.5211 \\
\hline
\end{tabular}


(a) growth $(\hat{\gamma})$ and retirement age $\left(R^{*}\right)$

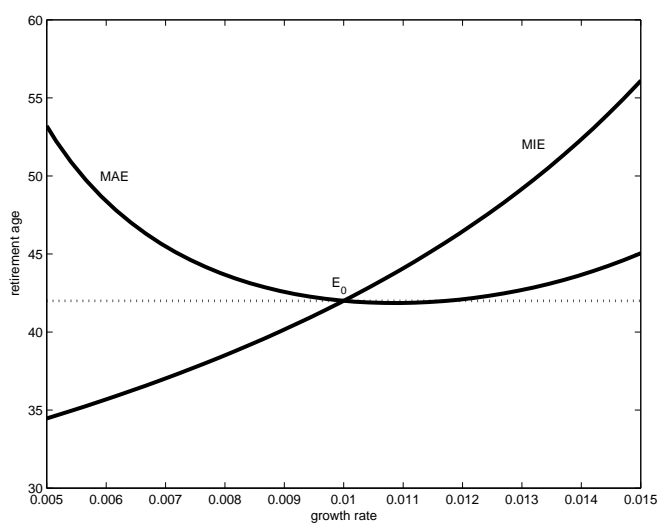

(c) labour supply $(L(u))$

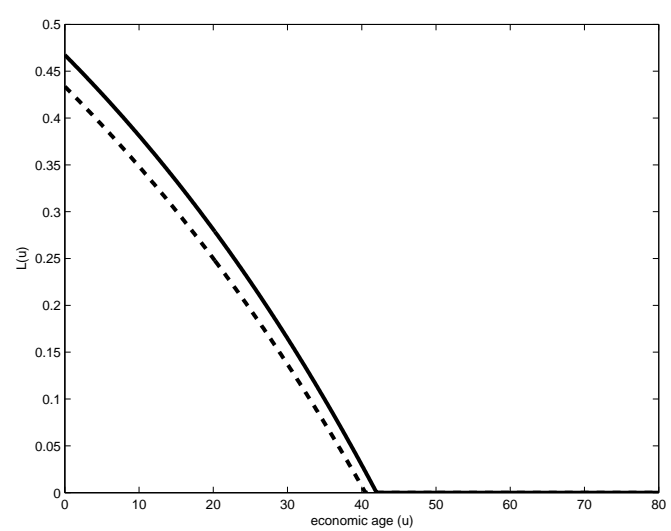

(b) scaled consumption newborns $(C(u) / w(0))$

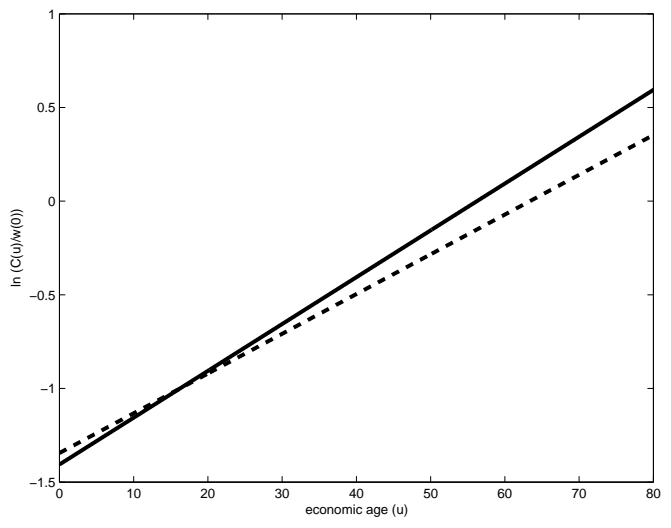

(d) scaled financial assets $(A(u) / w(0))$

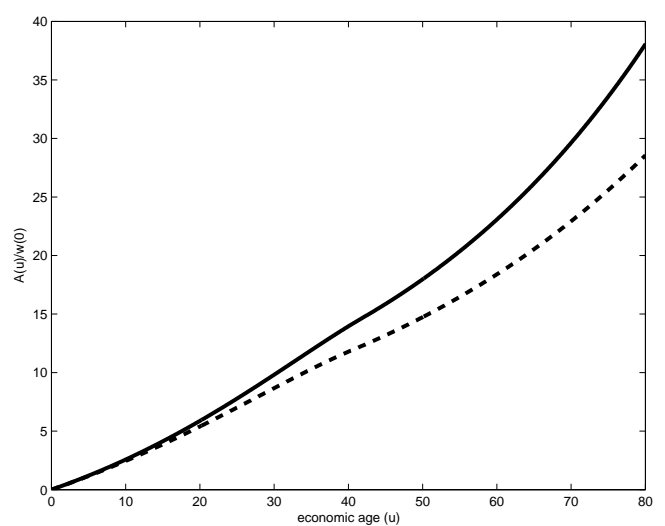

Figure 3: General equilibrium in the core model

The new steady-state age profiles for the imperfect annuity case have been illustrated in Figures 3(b)-(d) (see the dashed lines). The growth rate in individual consumption is reduced somewhat because $-(1-\theta) \mu$ features in equation (12). Figure 3(c) shows that the agent reduces labour supply at all age levels and thus retires earlier than under perfect annuities. Finally, Figure 3(d) shows that the age profile for scaled financial assets continues to be upward sloping, though it is lower than under perfect annuities. 


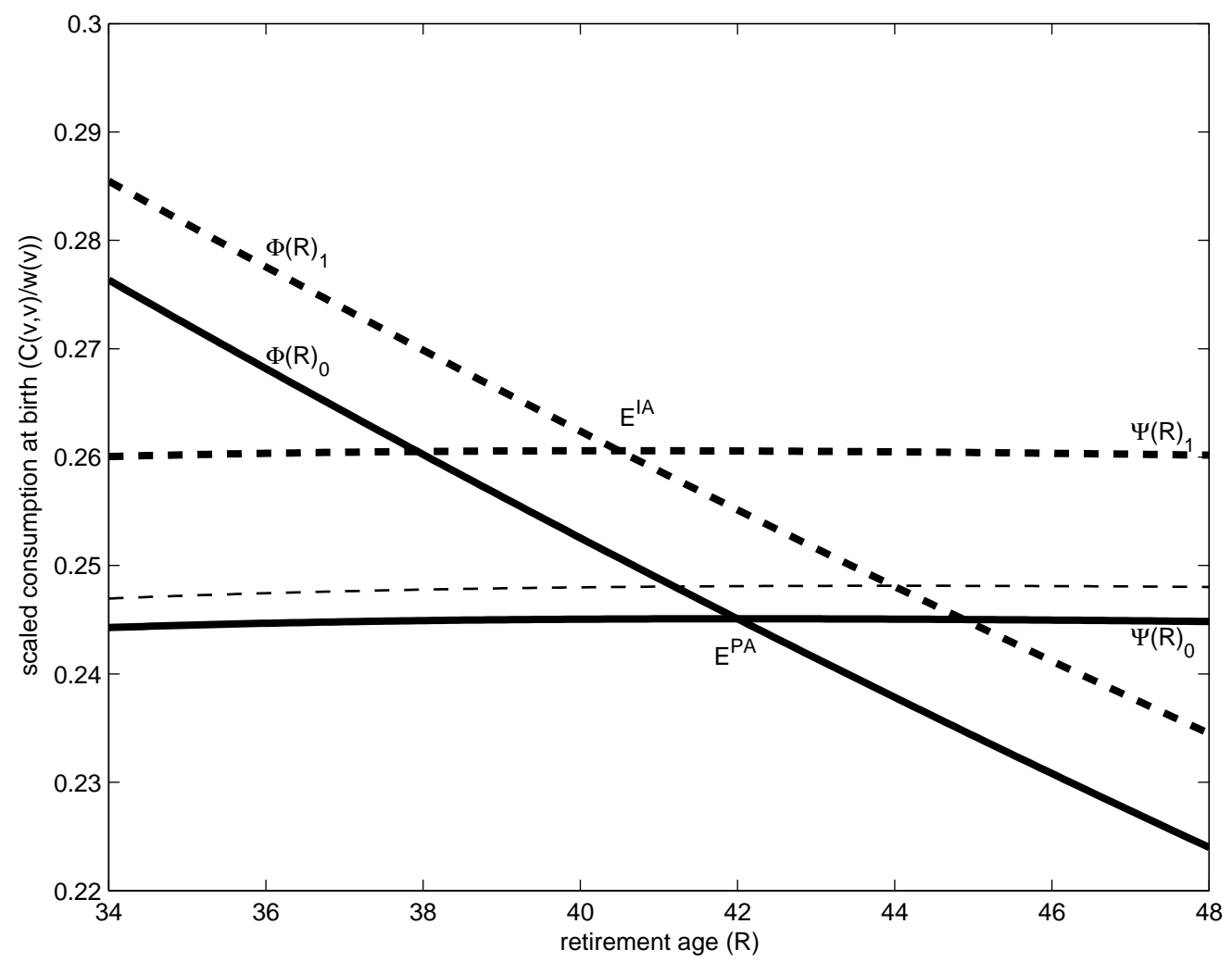

Figure 4: Imperfect annuities and the retirement date 


\section{Extensions}

In the previous section we used a calibrated version of the core model to show that an imperfection in the annuity market leads to a reduction in both the optimal retirement age and the macroeconomic growth rate. The core model, though useful for analytical purposes, suffers from a number of empirical deficiencies. These are:

(ED1). The age profile for consumption is monotonically increasing, whereas it is hump-shaped in reality (Gourinchas and Parker, 2002, and Fernández-Villaverde and Krueger, 2007).

(ED2). The age profile for labour supply is monotonically decreasing. In reality, labour supply is constant and age-invariant for most of working life and tapers off rapidly near the optimal retirement age (see, for example, McGrattan and Rogerson (2004) for the United States).

(ED3). Labour productivity is age-independent, whereas in reality it appears to be hump-shaped (cf. Hansen, 1993 and Rios-Rull, 1996).

(ED4). Under perfect annuities, the age profile for financial assets is monotonically rising. In reality, financial assets (a) display a hump-shaped profile, and (b) remain non-negative in old age (Huggett, 1996). Feature (a) can be mimicked by assuming imperfect annuities, but in that case assets become negative for very old agents, thus violating feature (b).

(ED5). To calibrate the model for a realistic retirement age and macroeconomic growth rate, an implausibly high efficiency parameter for capital must be postulated.

In this section we consider two important model extensions, namely age-dependent labour productivity and age-dependent mortality. In each case we study whether, and to what extent, the model extension under consideration can solve the empirical deficiencies of the core model. Both individual decisions and (simulated) general equilibrium effects are studied.

\subsection{Hump-shaped productivity}

In this section we directly address empirical deficiency (ED3) and assume that labour productivity of individuals is hump-shaped. An analytically useful age profile for productivity 
involves exponential terms:

$$
E(u)=\alpha_{0} e^{-\beta_{0} u}-\alpha_{1} e^{-\beta_{1} u},
$$

where $E(u)$ is labour productivity of a $u$-year old worker, and we assume that $\alpha_{0}>\alpha_{1}>0$, $\beta_{1}>\beta_{0}>0$, and $\alpha_{1} \beta_{1}>\alpha_{0} \beta_{0}$. We easily find that:

$$
\begin{aligned}
& E(0)=\alpha_{0}-\alpha_{1}>0, \quad \lim _{u \rightarrow \infty} E(u)=0 \\
& E^{\prime}(u)=-\beta_{0} \alpha_{0} e^{-\beta_{0} u}+\beta_{1} \alpha_{1} e^{-\beta_{1} u} \begin{cases}>0 & \text { for } 0 \leq u<\bar{u} \\
<0 & \text { for } u \geq \bar{u}\end{cases}
\end{aligned}
$$

where $\bar{u}$ is:

$$
\bar{u}=\frac{1}{\beta_{1}-\beta_{0}} \ln \left(\frac{\alpha_{1} \beta_{1}}{\alpha_{0} \beta_{0}}\right) .
$$

Labour productivity is non-negative throughout life, starts out positive, is rising during the first life phase, and declines thereafter.

The production side of the model is affected as follows. The total stock of efficiency units of labour at time $t$ is denoted by $N(t)$ and is defined in the usual way:

$$
N(t) \equiv \int_{-\infty}^{t} P(v, t) E(t-v) L(v, t) d v
$$

where $L(v, t)$ stands for labour supply in raw hours, and $P(v, t)$ is the size of cohort $v$ at time $t$. Replacing $L_{i}$ by $N_{i}$ in equation (1), and redefining $\kappa_{i} \equiv K_{i} / N_{i}$ and $\kappa \equiv K / N$, we find that (5) and (7) are still satisfied but (6) must be changed to:

$$
w(t) N(t)=\left(1-\varepsilon_{K}\right) Y(t),
$$

where $w(t)$ stands for the rental rate on efficiency units of labour. The wage faced at time $t$ by a worker born at time $v$ is thus given by:

$$
w(v, t) \equiv E(t-v) w(t)
$$

The household side of the model is affected as follows. In the household budget identity $(9), w(\tau)$ is replaced by $w(v, \tau)$. Along the balanced growth path, $w(v, \tau)$ can be written as:

$$
w(v, \tau)=w(v) e^{\hat{\gamma}(\tau-v)}\left[\alpha_{0} e^{-\beta_{0}(\tau-v)}-\alpha_{1} e^{-\beta_{1}(\tau-v)}\right],
$$


where we have used (36) and (42). The consumption Euler equation is still given by (12). Interestingly, with a hump-shaped wage profile, it may be optimal for the agent to delay labour market entry somewhat. Indeed, we now have two relevant dates for the working decision of an agent, namely the optimal entry date, $S^{*}$, and the optimal retirement date, $R^{*}{ }^{9}$ Obviously, we must have that $R^{*}>S^{*} \geq 0$. During working life $\left(S^{*} \leq \tau-v \leq R^{*}\right)$ the condition (13) still holds but with $w(v, \tau)$ replacing $w(\tau)$.

Scaled consumption of a newborn agent is given by:

$$
\frac{C(v, v)}{w(v)}=\frac{\varepsilon_{C}(\rho+\mu)}{\varepsilon_{C}+\left(1-\varepsilon_{C}\right)\left[e^{-(\rho+\mu) S^{*}}-e^{\left.-(\rho+\mu) R^{*}\right]}\right.} \cdot \frac{L I(v, v)}{w(v)},
$$

where $L I(v, v) / w(v)$ is defined as:

$$
\frac{L I(v, v)}{w(v)} \equiv \int_{S^{*}}^{R^{*}} E(s) e^{-(r-\hat{\gamma}+\theta \mu) s} d s+\frac{z}{r-\hat{\gamma}+\theta \mu} .
$$

For an interior solution (with $S>0$ ), the labour market entry condition is given by: ${ }^{10}$

$$
\frac{C(v, v)}{w(v)}=\frac{\varepsilon_{C}}{1-\varepsilon_{C}} E\left(S^{*}\right) e^{-[r-\hat{\gamma}-\rho-(1-\theta) \mu] S^{*}},
$$

whereas the retirement condition is given by:

$$
\frac{C(v, v)}{w(v)}=\frac{\varepsilon_{C}}{1-\varepsilon_{C}} E\left(R^{*}\right) e^{-[r-\hat{\gamma}-\rho-(1-\theta) \mu] R^{*}} .
$$

Equations (44) (with (45) substituted), (46), and (47) form a three-equation system with three unknowns, viz. $C(v, v) / w(v), S^{*}$, and $R^{*}$ (see Table $3(\mathrm{a})$ ). This system can be solved conditional on the macroeconomic variables, $\hat{\gamma}$ and $z$.

Using cross-section efficiency data for male workers aged between 18 and 70 from Hansen (1993, p. 74) we find the solid pattern in Figure 5(a). We interpolate these data by fitting equation (36) using non-linear least squares. We find the following estimates (t-statistics in brackets): $\alpha_{0}=4.494$ (fixed), $\hat{\alpha}_{1}=4.010$ (71.04), $\hat{\beta}_{0}=0.0231(24.20)$, and $\hat{\beta}_{1}=0.050$ (17.81). The fitted productivity profile is illustrated with dashed lines in Figure 5(a).

\footnotetext{
${ }^{9}$ As was the case in the core model of the previous section, household preferences and the redistribution scheme are such that $S^{*}$ and $R^{*}$ are generation independent, i.e. $S^{*}(v)=S^{*}$ and $R^{*}(v)=R^{*}$ for all $v$.

${ }^{10}$ It is not difficult to show that an interior solution for $S^{*}$ is obtained if the following condition is satisfied:

$$
\frac{C(v, v)}{w(v)}>\frac{\varepsilon_{C}}{1-\varepsilon_{C}} E(0) \text {. }
$$
}

If this condition is violated, then $L(v, v)$ attains an interior solution satisfying:

$$
\frac{C(v, v)}{w(v)}=\frac{\varepsilon_{C}}{1-\varepsilon_{C}} E(0)[1-L(v, v)] .
$$


Table 3: Balanced growth and retirement with age-dependent productivity

(a) Microeconomic relationships:

$$
\begin{aligned}
\frac{C(v, v)}{w(v)}= & \frac{\varepsilon_{C}(\rho+\mu)}{\varepsilon_{C}+\left(1-\varepsilon_{C}\right)\left[e^{-(\rho+\mu) S^{*}}-e^{\left.-(\rho+\mu) R^{*}\right]}\right.} \\
& \cdot\left[\int_{S^{*}}^{R^{*}} E(s) e^{-(r-\hat{\gamma}+\theta \mu) s} d s+\frac{z}{r-\hat{\gamma}+\theta \mu}\right] \\
\frac{C(v, v)}{w(v)}= & \frac{\varepsilon_{C}}{1-\varepsilon_{C}} E\left(S^{*}\right) e^{-(r-\hat{\gamma}-\rho-(1-\theta) \mu) S^{*}} \\
\frac{C(v, v)}{w(v)}= & \frac{\varepsilon_{C}}{1-\varepsilon_{C}} E\left(R^{*}\right) e^{-(r-\hat{\gamma}-\rho-(1-\theta) \mu) R^{*}}
\end{aligned}
$$

(b) Macroeconomic relationships:

$$
\begin{aligned}
z & =\mu(1-\theta) \frac{k(t)}{w(t)} \\
\hat{\gamma} \equiv & \frac{\dot{k}(t)}{k(t)}=r-\pi+\left[n-\frac{c(t)}{w(t)}\right] \cdot \frac{w(t)}{k(t)} \\
\frac{w(t) n}{k(t)}= & \left(1-\varepsilon_{K}\right) Z_{0} \\
n \equiv & \int_{S^{*}}^{R^{*}} \beta E(s) e^{-\beta s} d s \\
& -\beta e^{-\beta R^{*}} E\left(R^{*}\right) \frac{e^{[\hat{\gamma}+\beta+\rho+(1-\theta) \mu-r]\left(R^{*}-S^{*}\right)}-1}{\hat{\gamma}+\beta+\rho+(1-\theta) \mu-r} \\
\frac{c(t)}{w(t)} \equiv & \frac{\beta}{\hat{\gamma}+\beta+\rho+(1-\theta) \mu-r} \cdot \frac{C(v)}{w(v)}
\end{aligned}
$$

Definitions: Endogenous are $C(v, v) / w(v), S^{*}, R^{*}, z, \hat{\gamma}, n, w(t) / k(t)$, and $c(t) / w(t)$. Parameters: birth rate $\beta$, mortality rate $\mu$, population growth rate $\pi \equiv \beta-\mu$, imperfection annuities $\theta$, rate of time preference $\rho$, capital coefficient in the technology $\varepsilon_{K}$, consumption coefficient in tastes $\varepsilon_{C}$, scale factor in the technology $Z_{0}$. The interest rate is $r \equiv \varepsilon_{K} Z_{0}-\delta$, where $\delta$ is the depreciation rate of capital. 
(a) efficiency profile $(E(u))$

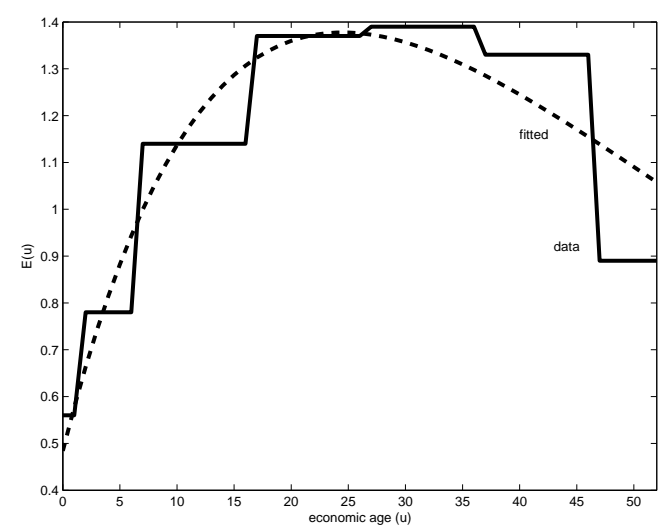

(c) scaled consumption newborns $(C(u) / w(0))$

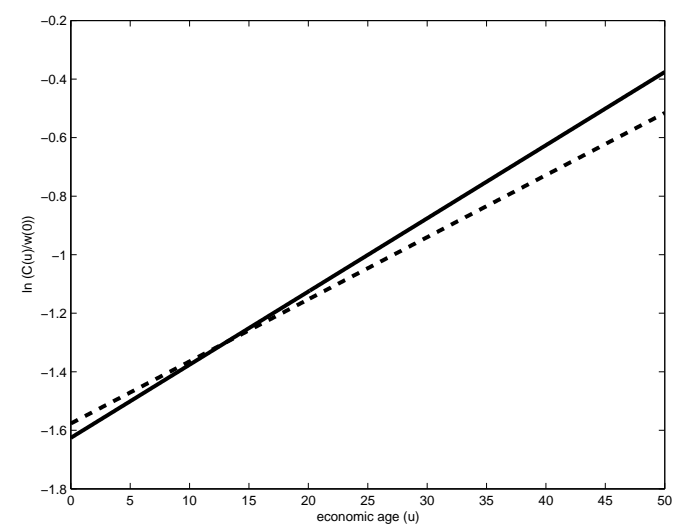

(b) labour supply $(L(u))$

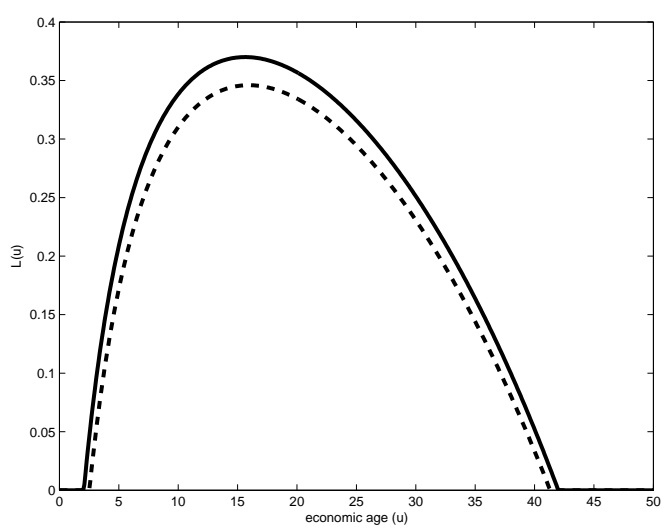

(d) scaled financial assets $(A(u) / w(0))$

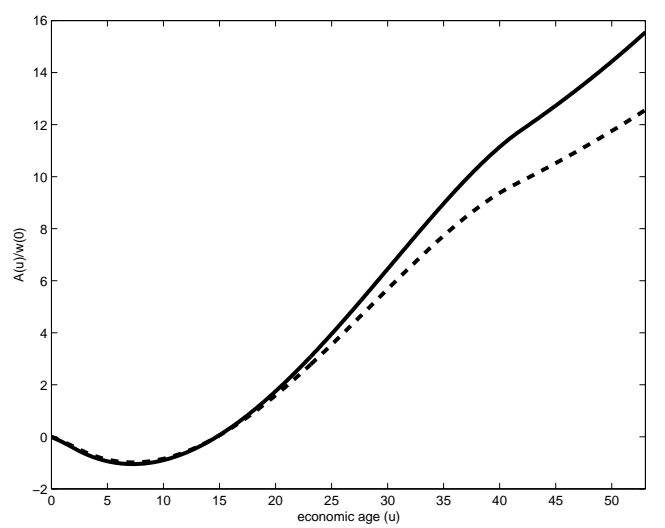

Figure 5: General equilibrium with age-dependent labour productivity 
We have collected the key equations of the macroeconomic growth model in Table 3. Effectively this table provides the hump-shaped productivity analogue to Table 1. Compared to Table 1, the main changed are as follows. First, there is an additional equation governing the entry decision of households. Second, total labour supply is measured in efficiency units (i.e. $n$ rather than $l$ features in (T3.5)-(T3.7)). Third, the labour productivity age profile features prominently in (T3.2)-(T3.3) and (T3.7). The key features of the initial steady-state growth path have been reported in the first column of Table 2(b).

Figures 5(b)-(d) provide a visualization of the extended model. The key panel to consider is $5(\mathrm{~b})$, which shows that with a hump-shaped productivity profile, the labour supply profile also features a hump-shaped pattern. This model extension thus somewhat alleviates empirical deficiency (ED2) of the core model. That is, we now have a labour supply profile that increases rapidly in young age, briefly touches a plateau and then drops to zero (i.e. retirement) quickly. Interestingly, the remaining empirical deficiencies (ED1) and (ED4)-(ED5) are not solved by the introduction of age dependent labour productivity. Consumption and assets are not hump shaped, and the required capital efficiency parameter, though lower than for the core model, is still too high $\left(\varepsilon_{K}=0.8954\right)$.

As before, the dashed lines in Figures 5(b)-(d) visualize the implications of an imperfect annuity market (captured by $\theta=0.7$ ). The key features of the new steady-state growth path have been reported in column 2 of Table 2(b). Just as in the core model, agents retire earlier when annuity markets are imperfect. Furthermore, and in contrast to the core model, we find that agents also delay labour market entry by almost half a year. Hence, the composite impact of an imperfect annuity market on individual decisions is that agents delay labour market entry, work less during working life and retire early. In general equilibrium this leads to a substantial reduction in economic growth. Interestingly, the effect on economic growth is very similar for the core model and the extended model.

\subsection{Age-dependent mortality}

In this section we assume $E(u)=1$ for all $u$ and instead augment the core model by assuming age-dependent mortality. For ease of exposition, we use a demographic process which incorporates a finite maximum age; the BCL-model suggested by Boucekkine et al. (2002). 
In this model, the surviving fraction up to age $u$ (from the perspective of birth) is given by:

$$
1-\Phi(u) \equiv \frac{\mu_{0}-e^{\mu_{1} u}}{\mu_{0}-1},
$$

with $\mu_{0}>1$ and $\mu_{1}>0$. For this demographic process, $\bar{D}=\left(1 / \mu_{1}\right) \ln \mu_{0}$ is the maximum attainable age, whilst the instantaneous mortality rate at age $u$ is given by: ${ }^{11}$

$$
\mu(u) \equiv \frac{\Phi^{\prime}(u)}{1-\Phi(u)}=\frac{\mu_{1} e^{\mu_{1} u}}{\mu_{0}-e^{\mu_{1} u}} .
$$

The mortality rate is increasing in age and becomes infinite at $u=\bar{D}$.

We use data from age 18 onward for the Dutch cohort that was born in 1960. Following Heijdra and Romp (2008), we denote the actual surviving fraction up until model age $u_{i}$ by $S_{i}$, and estimate the parameters of the parametric distribution function by means of non-linear least squares. The model to be estimated is thus:

$$
S_{i}=1-\Phi\left(u_{i}\right)+\varepsilon_{i}=d\left(u_{i} \leq D\right) \cdot \frac{\mu_{0}-e^{\mu_{1} u_{i}}}{\mu_{0}-1}+\varepsilon_{i}
$$

where $d\left(u_{i} \leq \bar{D}\right)=1$ for $u_{i} \leq \bar{D}$, and $d\left(u_{i} \leq \bar{D}\right)=0$ for $u_{i}>\bar{D}$, and $\varepsilon_{i}$ is the stochastic error term. We find the following estimates (with t-statistics in brackets): $\hat{\mu}_{0}=122.643$ (11.14), $\hat{\mu}_{1}=0.0680$ (48.51). The standard error of the regression is $\hat{\sigma}=0.02241$, and the implied estimate for $\bar{D}$ is 70.75 model years (i.e., the maximum age in biological years is 88.75). Figure 6(a) depicts the actual and fitted survival rates with, respectively, solid and dashed lines. Up to age 69, the BCL model fits the data rather well. For higher ages the fit deteriorates as the BCL model fails to capture the fact that some people are expected to live to very ripe old ages in reality.

Using the same data, we also estimate the parameter of the Blanchard demography, by running the following regression by means of non-linear least squares: $S_{i}=e^{-\mu u_{i}}+\varepsilon_{i}$. We find $\hat{\mu}=0.0126$ (11.41), and $\hat{\sigma}=0.2466$. The dotted line in Figure 6a depicts the fitted

\footnotetext{
${ }^{11}$ This result follows from the fact that $1-\Phi(\bar{D})=0$ iff $e^{\mu_{1} \bar{D}}=\mu_{0}$. Note furthermore that (for $\left.0<u, s<\bar{D}\right)$, the cumulative mortality rate is:$$
M(u) \equiv-\ln [1-\Phi(u)]
$$

so that the exponential discounting factors are given by:

$$
e^{-M(s)} \equiv \frac{\mu_{0}-e^{\mu_{1} s}}{\mu_{0}-1}, \quad e^{M(s)} \equiv \frac{\mu_{0}-1}{\mu_{0}-e^{\mu_{1} s}}
$$


(a) mortality process $(1-\Phi(u))$

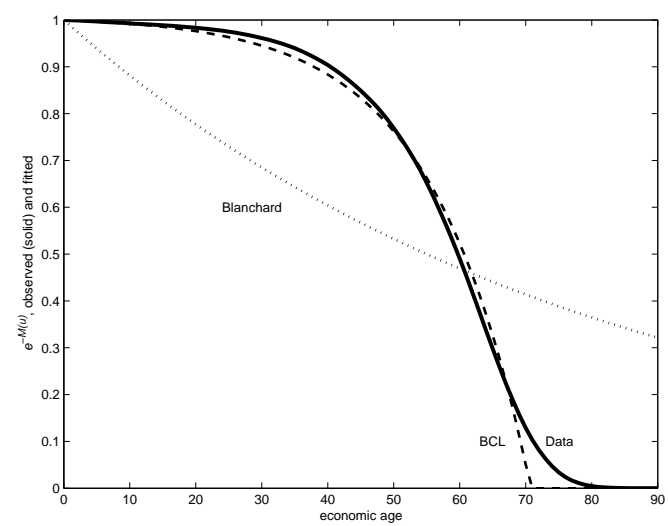

(c) scaled consumption newborns $(C(u) / w(0))$

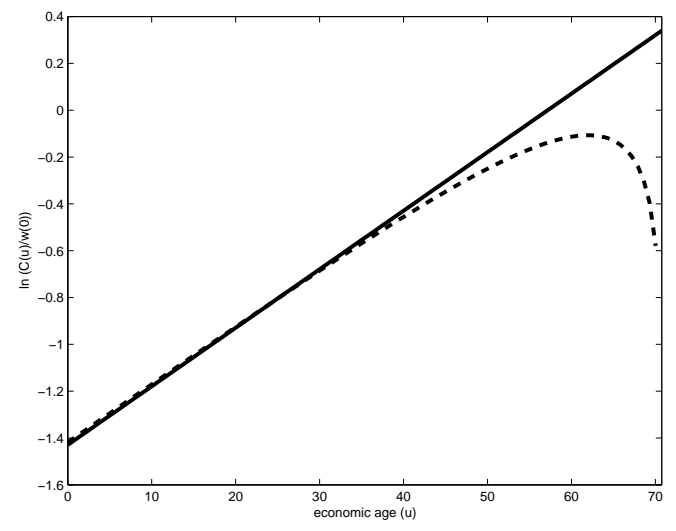

(b) labour supply $(L(u))$

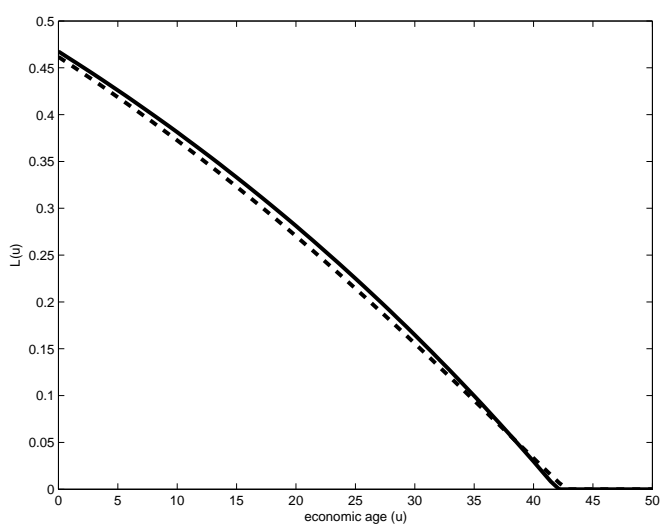

(d) scaled financial assets $(A(u) / w(0))$

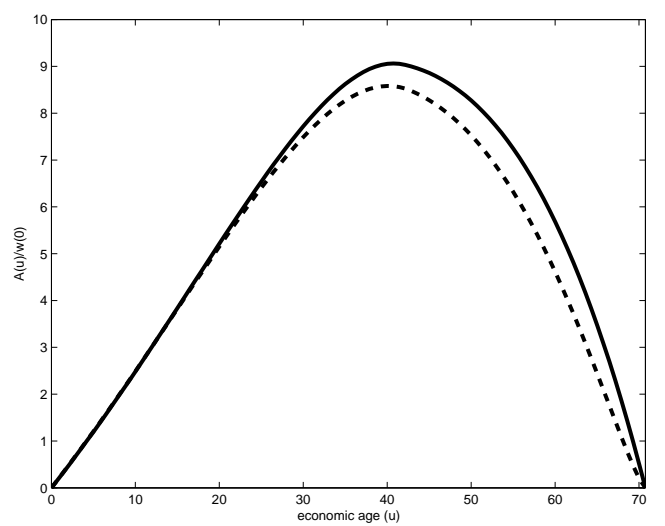

Figure 6: General equilibrium with age-dependent mortality 
survival rates implied by the Blanchard demography. The fit is much worse than that of the BCL model. Relative to the data, the Blanchard model "kills off" the young too quickly and the old too slowly.

In the presence of age-dependent mortality, the core model is changed as follows. First, as is explained in Heijdra and Romp (2008, p. 92), the lifetime utility function (8) is now given by:

$$
E \Lambda(v, t) \equiv e^{M(t-v)} \cdot \int_{t}^{v+\bar{D}} \ln \left[C(v, \tau)^{\varepsilon_{C}} \cdot[1-L(v, \tau)]^{\left(1-\varepsilon_{C}\right)}\right] \cdot e^{-\rho(\tau-t)-M(\tau-v)} d \tau,
$$

where (a) the maximum possible age is incorporated in the upper limit of the integral, and (b) the discounting factor due to lifetime uncertainty, $e^{-M(\tau-v)}=\left(\mu_{0}-e^{\mu_{1}(\tau-v)}\right) /\left(\mu_{0}-1\right)$, depends on the agent's age at some future time $\tau$.

Second, the annuity rate given in (10) above is modified to reflect the fact that the mortality rate depends on age:

$$
r^{A}(\tau-v) \equiv r+\theta \mu(\tau-v), \quad(\text { for } 0 \leq \tau-v<\bar{D}) .
$$

Older agents attract a higher annuity rate than younger agents do because they feature a higher mortality rate (note that at age $\tau-v=\bar{D}$ no life insurance is available). Utility maximization gives rise to a consumption Euler equation that is different from the one given in (12) above:

$$
\frac{\dot{C}(v, \tau)}{C(v, \tau)}=r-\rho-(1-\theta) \mu(\tau-v)
$$

Provided annuities are imperfect $(\theta<1)$, optimal consumption growth is age dependent.

The key expressions characterizing individual behaviour are given in equations (T4.1)(T4.3) in Table 4. Equation (T4.1) gives the expression for scaled consumption at birth. It contains specific values for a general demography-dependent function that is defined as follows:

$$
\Xi\left(\lambda_{1}, \lambda_{2}\right)_{u_{0}}^{u_{1}}=\int_{u_{0}}^{u_{1}} e^{-\lambda_{1} s} \cdot\left[\frac{\mu_{0}-e^{\mu_{1} s}}{\mu_{0}-1}\right]^{\lambda_{2}} d s
$$

with $0 \leq u_{0}<u_{1} \leq \bar{D}$ and $\lambda_{2} \geq 0$. Provided $\lambda_{1}$ is finite, the integral exists and is strictly positive. It follows that $\Xi(r-\hat{\gamma}, \theta)_{S^{*}}^{R^{*}}>0, \Xi(r-\hat{\gamma}, \theta)_{0}^{\bar{D}}>0, \Xi(\rho, 1)_{S^{*}}^{R^{*}}>0$, and $\Xi(\rho, 1)_{0}^{\bar{D}}>0$, so scaled newborn consumption is positive and depends positively on the amount of transfers. 
Table 4: Balanced growth and retirement with age-dependent mortality

(a) Microeconomic relationships:

$$
\begin{aligned}
\frac{C(v, v)}{w(v)} & =\frac{\varepsilon_{C} \Xi(r-\hat{\gamma}, \theta)_{S^{*}}^{R^{*}}+\varepsilon_{C} \Xi(r-\hat{\gamma}, \theta)_{0}^{\bar{D}} \cdot z}{\left(1-\varepsilon_{C}\right) \Xi(\rho, 1)_{S^{*}}^{R^{*}}+\varepsilon_{C} \Xi(\rho, 1)_{0}^{\bar{D}}} \\
\frac{C(v, v)}{w(v)} & =\frac{\varepsilon_{C}}{1-\varepsilon_{C}} e^{-(r-\hat{\gamma}-\rho) S^{*}+(1-\theta) M\left(S^{*}\right)} \\
\frac{C(v, v)}{w(v)} & =\frac{\varepsilon_{C}}{1-\varepsilon_{C}} e^{-(r-\hat{\gamma}-\rho) R^{*}+(1-\theta) M\left(R^{*}\right)}
\end{aligned}
$$

(b) Macroeconomic relationships:

$$
\begin{aligned}
z & =(1-\theta) \cdot \int_{0}^{\bar{D}} \beta e^{-(\pi+\hat{\gamma}) u-M(u)} \mu(u) \frac{A(v, v+u)}{w(v)} d u \\
\hat{\gamma} & \equiv \frac{\dot{k}(t)}{k(t)}=r-\pi+\left[l-\frac{c(t)}{w(t)}\right] \cdot \frac{w(t)}{k(t)} \\
\frac{w(t) l}{k(t)} & =\left(1-\varepsilon_{K}\right) Z_{0} \\
l & =\beta \cdot\left[\Xi(\pi, 1)_{S^{*}}^{R^{*}}-\frac{1-\varepsilon_{C}}{\varepsilon_{C}} \frac{C(v, v)}{w(v)} \cdot \Xi(\pi+\rho+\hat{\gamma}-r, 2-\theta)_{S^{*}}^{R^{*}}\right] \\
\frac{c(t)}{w(t)} & \equiv \frac{C(v, v)}{w(v)} \cdot \beta \Xi(\pi+\rho+\hat{\gamma}-r, 2-\theta)_{0}^{\bar{D}}
\end{aligned}
$$

Definitions: Endogenous are $C(v, v) / w(v), S^{*}, R^{*}, z, \hat{\gamma}, l, w(t) / k(t)$, and $c(t) / w(t)$. Parameters: birth rate $\beta$, aggregate mortality rate $\bar{\mu}$, population growth rate $\pi \equiv \beta-\bar{\mu}$, imperfection annuities $\theta$, rate of time preference $\rho$, capital coefficient in the technology $\varepsilon_{K}$, consumption coefficient in tastes $\varepsilon_{C}$, scale factor in the technology $Z_{0}$. The interest rate is $r \equiv \varepsilon_{K} Z_{0}-\delta$, where $\delta$ is the depreciation rate of capital. 
Interestingly, despite the fact that productivity is age-independent, equation (T4.2) show that with imperfect annuities it is in principle possible for the individual agent to postpone labour market entry somewhat, i.e. to choose $S^{*}>0$. With a realistic demography, however, this scenario does not materialize, i.e. in practice labour market entry is immediate and $S^{*}=0$. Intuitively, this results from the fact that the mortality process only cuts in toward the end of the agent's life.

The third aspect for which the core model is modified as a result of age-dependent mortality concerns the demographic system. As is shown in Heijdra and Romp (2008, p. 94), with age-dependent mortality the demographic steady-state equilibrium has the following features:

$$
\begin{aligned}
\frac{1}{\beta} & =\Xi(\pi, 1)_{0}^{\bar{D}}, \\
p(v, t) & \equiv \frac{P(v, t)}{P(t)} \equiv \beta e^{-\pi(t-v)-M(t-v)},
\end{aligned}
$$

where $\beta$ is the crude birth rate (as before), $\pi$ is the growth rate of the population, and $p(v, t)$ is the relative size of cohort $v$ at time $t \geq v$. For a given birth rate, equation (55) determines the unique population growth rate consistent with the demographic steady state. The average population-wide mortality rate, $\bar{\mu}$, follows residually from the fact that $\pi \equiv \beta-\bar{\mu} .{ }^{12}$ Equation (55) simply generalizes (21) to the case with age-dependent mortality.

The macroeconomic part of the model is given by equations (T4.4)-(T4.8) in Table 4. Compared to the core model, the main changes are found in (T4.4) and (T4.7)-(T4.8). In (T4.4), transfers can no longer be related to a single aggregate variable but must be computed (numerically) by using the scaled wealth paths of existing cohorts. Expressions (T4.7)-(T4.8) generalize (T1.6)-(T1.7), making use of the $\Xi\left(\lambda_{1}, \lambda_{2}\right)_{u_{0}}^{u_{1}}$ function defined in (54) above.

Just as for the previous two models, we calibrate the model for an initial steady state with perfect annuities $(\theta=1)$, a growth rate of one percent $(\hat{\gamma}=0.01)$, and an optimal retirement age of 42 years $\left(R^{*}=42\right)$. The key features of the initial steady-state growth path have been

\footnotetext{
${ }^{12}$ The average mortality rate is defined as:

$$
\bar{\mu} \equiv \frac{1}{P(t)} \cdot \int_{t-\bar{D}}^{t} \mu(t-v) P(v, t) d v=\beta \int_{-\bar{D}}^{t} \mu(t-v) e^{-\pi(t-v)-M(t-v)} d v .
$$
}

For the BCL demography we find:

$$
\bar{\mu}=\beta \cdot \int_{0}^{\bar{D}} \mu(s) e^{-\pi s-M(s)} d s=\frac{\beta \mu_{1}}{\mu_{0}-1} \cdot \int_{0}^{\bar{D}} e^{\left(\mu_{1}-\pi\right) s} d s=\frac{\beta \mu_{1}}{\mu_{0}-1} \cdot \frac{\mu_{0} e^{-\pi \bar{D}}-1}{\mu_{1}-\pi} .
$$

See Heijdra and Mierau (2009a) for further details. 
reported in the first column of Table 2(c). As was mentioned above, labour market entry is immediate for the cases considered in Table 2(c).

Figures 6(b)-(d) provide a visualization of the extended model. The key panels to consider are 6(c) and 6(d). With imperfect annuities, consumption features a hump-shaped pattern thus addressing empirical deficiency (ED1)-see the dashed lines in Figure 6(c). This finding is in line with Yaari (1965), Abel (1985), Bütler (2001), and Hansen and İmrohoroğlu (2008): with imperfect annuities the mortality rate features in the Euler equation. Hence, if the mortality rate is age-dependent, agents will discount consumption later on in life more heavily, thus creating a hump-shaped profile. From an empirical point of view it should be noted that we-like Bütler (2001) and Hansen and İmrohoroğlu (2008)-also find that the hump occurs too late in life. Also, as is illustrated in Figure 6(d), financial assets feature a hump-shaped pattern both with perfect and with imperfect annuities. The model extension thus fixes empirical deficiency (ED4) to a large extent. Finally, empirical deficiency (ED5) is reduced somewhat in this extension as the required efficiency parameter for capital is equal to $\varepsilon_{K}=0.74$ (rather than 0.92 in the core model).

As before, the dashed lines in Figures 6(b)-(d) visualize the implications of an imperfect annuity market (captured by $\theta=0.7$ ). The key features of the new steady-state growth path have been reported in column 2 of Table 2(c). Just as in the core model, individual and aggregate saving and thus the macroeconomic growth rate are all lower when annuity markets are imperfect rather than perfect. ${ }^{13}$ Furthermore, and in contrast to both the core model and the model with age-dependent productivity, we now find that agents also delay labour market exit by almost three-quarters of year. Hence, the composite impact of an imperfect annuity market on individual decisions is that agents work slightly fewer hours during most of their working life, but retire somewhat later thus limiting the fall in the aggregate supply of labour. In general equilibrium this retirement effect explains why the reduction in economic growth is much smaller than for the previous two models.

In contrast to the core model, the calibration results of the model with a realistic demographic structure suggest a less pronounced effect of the annuity market imperfection; compare panels (a) and (c) in Table 2. Instead of experiencing a reduction in the economic

\footnotetext{
${ }^{13}$ This finding regarding growth has previously been highlighted by Abel (1985) and Fuster (1999) who suggest that capital accumulation decreases with imperfect annuities provided (i) the elasticity of intertemporal substitution is no less than unity and (ii) there is steady-state growth.
} 
(a) imperfection $((1-\theta) \mu(u))$

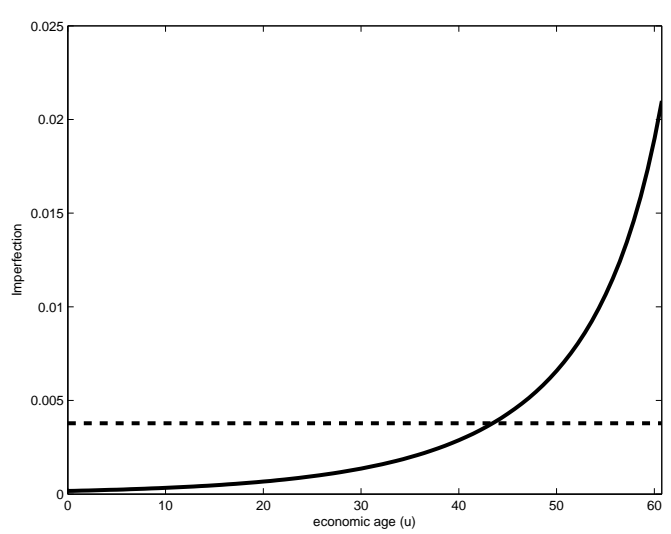

(b) cohort size $(p(u))$

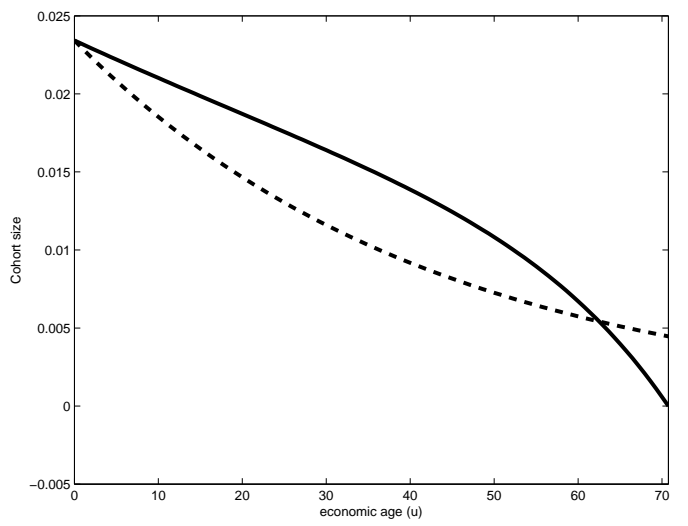

Figure 7: The annuity market imperfection

growth rate of 28 basis points, in the extended model we see a rather small reduction of only 6 basis points. Furthermore, instead of retiring 18 months early, agents now delay retirement by almost 8 months. To appreciate the origin of these effects, note Figures 7(a)-(b). Figure 7(a) visualizes the annuity market imperfection faced by the agent over the life-cycle. The dashed line shows the imperfection for the Blanchard mortality process whilst the solid line depicts the imperfection for the realistic case. From here it is immediately clear that the Blanchard mortality process overstates the magnitude of the annuity market imperfection for a substantial part of the life-cycle. In contrast, for a realistic demography the annuity market imperfection only becomes an issue later on in life. Furthermore, as can be seen in Figure 7 (b), the relative size of cohorts that are actually affected is quite small. Thus, both the individual and the aggregate effect of annuity market imperfections is much less pronounced with a realistic demography.

\subsection{Full model}

In this section we visualize the full model, simultaneously incorporating age-dependent labour productivity and mortality. The key equations for the full model have been collected in Table 5 , whilst Figure 8 visualizes some of its salient life-cycle features. Finally, the quantitative effect of imperfect annuities are reported in Table 2(d).

Figure 8(a) plots the right-hand sides of (T5.2) and (T5.3) as a function of age. For $\theta=1$, 
there is a unique entry age $\left(S^{*}=2.06\right.$, at point $\left.\mathrm{A}\right)$ and a unique retirement age $\left(R^{*}=42\right.$, at point $\mathrm{B})$. In contrast, for $\theta=0.7$, there appears to be a second labour market entry point located to the right of point B. This point is not feasible, however, because we assume that labour market exit is an absorbing state. Hence, also for $\theta=0.7$, there are unique entry and exit ages, i.e. $S^{*}=2.09$ and $R^{*}=42.15$-see Table $2(\mathrm{~d})$.

Figure 8 (b) shows the age profile for labour supply. It is hump-shaped because labour productivity is, i.e. Figure 8(b) looks very much like Figure 5(b) above.

Figure $8(\mathrm{~d})$ shows the age profile for financial assets. This figures captures the main features of Figure 6(d), but adds a borrowing period at the start of life. Agents delay labour market entry and-upon entry-face rather low wages and supply few hours early on in life. They finance their rising consumption profile by borrowing during that first life phase.

Interestingly, the quantitative effects of $\theta$ are rather small, as is revealed in Table 2(d), column (i). First, the effect on the retirement age is very small because the age-effects in productivity and mortality offset each other. Second, the mortality effect virtually eliminates the positive effect on the labour market entry age. Third, as the comparison between panels (b) to (d) in Table 2 reveals, the mortality effect constitutes the dominant mechanism by which economic growth is reduced in the full model. Growth only falls by 9 basis points (rather than 28 basis points for the core model). Finally, we note that empirical deficiency (ED5) is reduced by quite a bit in the full model as the required efficiency parameter for capital is equal to $\varepsilon_{K}=0.57$ (rather than 0.92 in the core model).

\subsection{The role of transfers in the full model}

Up until now we have focused on the situation where the profits made by the annuity firms are redistributed toward the agents in the form of a lump-sum transfer. These transfers have allowed us to focus solely on the substitution effect of the annuity market imperfection. However, in order to study the full (i.e. income and substitution) effect of the imperfection we need to consider an alternative general equilibrium mechanism by which the profits of the annuity firms are spent. In this subsection we assume that the government uses the funds for non-productive spending. We refer the reader to Heijdra and Mierau (2009a) for detailed derivations of the new equilibrium.

Compared to Table 5, there are two major changes. First, transfers are zero both with 
Table 5: Balanced growth and retirement with age-dependent productivity and mortality

(a) Microeconomic relationships:

$$
\begin{aligned}
\frac{C(v, v)}{w(v)}= & \frac{\alpha_{0} \varepsilon_{C} \Xi\left(r+\beta_{0}-\hat{\gamma}, \theta\right)_{S^{*}}^{R^{*}}-\alpha_{1} \varepsilon_{C} \Xi\left(r+\beta_{1}-\hat{\gamma}, \theta\right)_{S^{*}}^{R^{*}}}{\left(1-\varepsilon_{C}\right) \Xi(\rho, 1)_{S^{*}}^{R^{*}}+\varepsilon_{C} \Xi(\rho, 1)_{0}^{\bar{D}}} \\
& +\frac{\varepsilon_{C} \Xi(r-\hat{\gamma}, \theta)_{0}^{\bar{D}} \cdot z}{\left(1-\varepsilon_{C}\right) \Xi(\rho, 1)_{S^{*}}^{R^{*}}+\varepsilon_{C} \Xi(\rho, 1)_{0}^{\bar{D}}} \\
\frac{C(v, v)}{w(v)}= & \frac{\varepsilon_{C}}{1-\varepsilon_{C}} E\left(S^{*}\right) e^{-(r-\hat{\gamma}-\rho) S^{*}+(1-\theta) M\left(S^{*}\right)} \\
\frac{C(v, v)}{w(v)}= & \frac{\varepsilon_{C}}{1-\varepsilon_{C}} E\left(R^{*}\right) e^{-(r-\hat{\gamma}-\rho) R^{*}+(1-\theta) M\left(R^{*}\right)}
\end{aligned}
$$

(b) Macroeconomic relationships:

$$
\begin{aligned}
z= & (1-\theta) \cdot \int_{0}^{\bar{D}} \beta e^{-(\pi+\hat{\gamma}) u-M(u)} \mu(u) \frac{A(v, v+u)}{w(v)} d u \\
\hat{\gamma} \equiv & \frac{\dot{k}(t)}{k(t)}=r-\pi+\left[n-\frac{c(t)}{w(t)}\right] \cdot \frac{w(t)}{k(t)} \\
\frac{w(t) n}{k(t)}= & \left(1-\varepsilon_{K}\right) Z_{0} \\
n= & \beta \cdot\left[\alpha_{0} \Xi\left(\pi+\beta_{0}, 1\right)_{S^{*}}^{R^{*}}-\alpha_{1} \Xi\left(\pi+\beta_{1}, 1\right)_{S^{*}}^{R^{*}}\right. \\
& \left.-\frac{1-\varepsilon_{C}}{\varepsilon_{C}} \frac{C(v, v)}{w(v)} \cdot \Xi(\pi+\rho+\hat{\gamma}-r, 2-\theta)_{S^{*}}^{R^{*}}\right] \\
\frac{c(t)}{w(t)} \equiv & \frac{C(v, v)}{w(v)} \cdot \beta \Xi(\pi+\rho+\hat{\gamma}-r, 2-\theta)_{0}^{\bar{D}}
\end{aligned}
$$

Definitions: Endogenous are $C(v, v) / w(v), S^{*}, R^{*}, z, \hat{\gamma}, l, w(t) / k(t)$, and $c(t) / w(t)$. Parameters: birth rate $\beta$, aggregate mortality rate $\bar{\mu}$, population growth rate $\pi \equiv \beta-\bar{\mu}$, imperfection annuities $\theta$, rate of time preference $\rho$, capital coefficient in the technology $\varepsilon_{K}$, consumption coefficient in tastes $\varepsilon_{C}$, scale factor in the technology $Z_{0}$. The interest rate is $r \equiv \varepsilon_{K} Z_{0}-\delta$, where $\delta$ is the depreciation rate of capital. 
(a) entry/exit condition

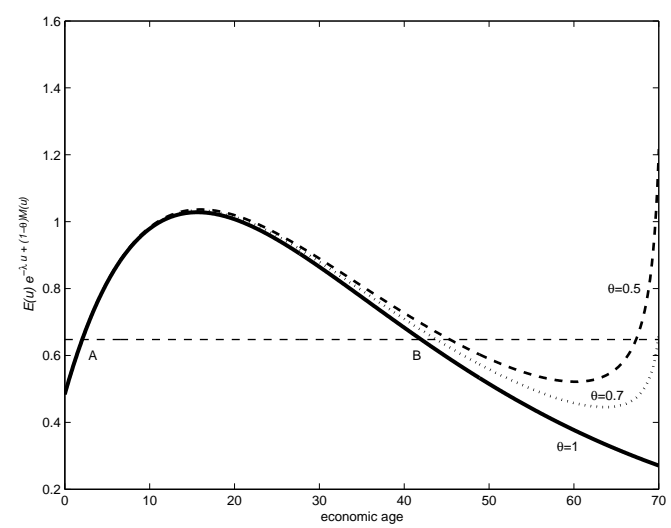

(c) scaled consumption newborns $(C(u) / w(0))$

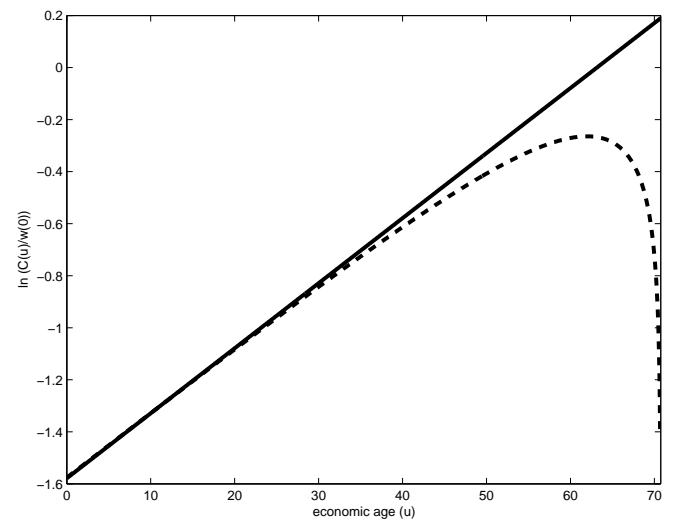

(b) labour supply $(L(u))$

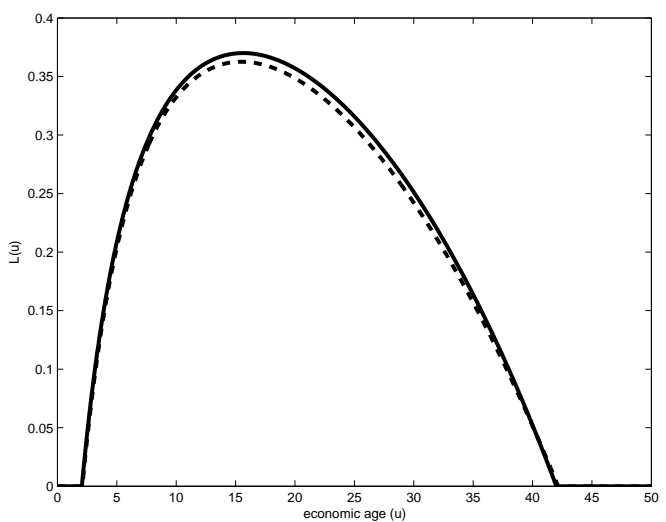

(d) scaled financial assets $(A(u) / w(0))$

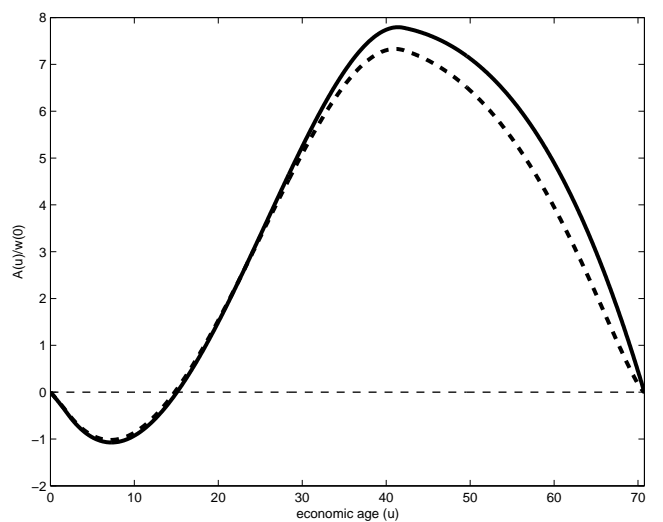

Figure 8: General equilibrium with age-dependent productivity and mortality 
(a) labour supply $(L(u))$

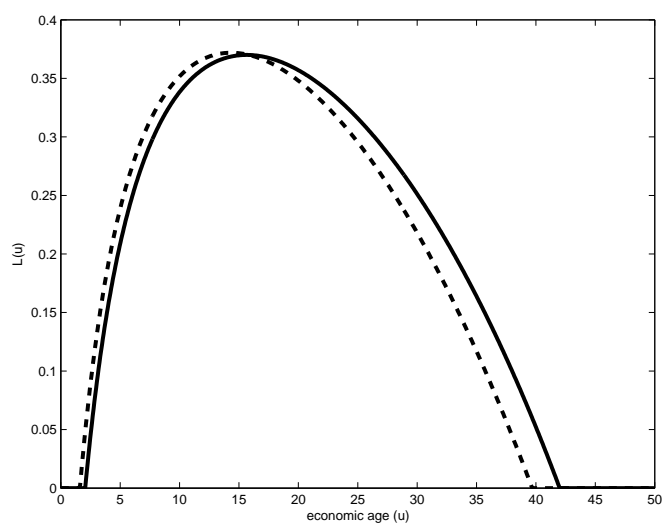

(b) scaled financial assets $(A(u) / w(0))$

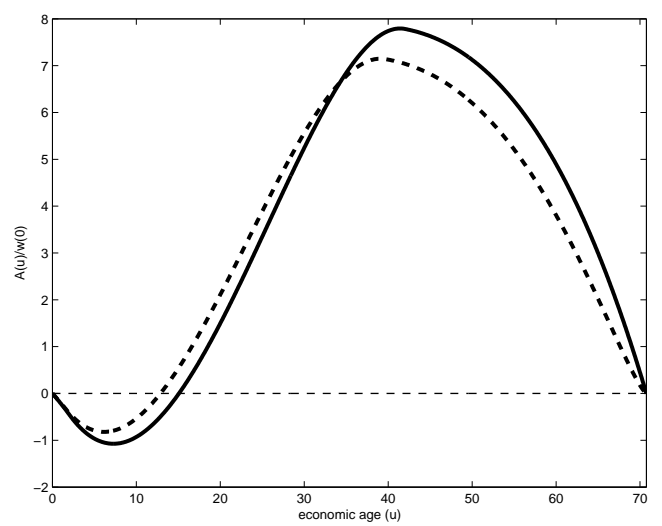

Figure 9: Full model with useless government spending

perfect and imperfect annuities. Second, the imperfection surfaces directly in the relationship for the growth rate. Indeed, equation (T5.5) is replaced by:

$$
\hat{\gamma}=\frac{\dot{k}(t)}{k(t)}=r-\pi-(1-\theta) \cdot \frac{w(t) \Gamma}{k(t)}+\left[n-\frac{c(t)}{w(t)}\right] \frac{w(t)}{k(t)},
$$

where $w(t) \Gamma$ is given by:

$$
w(t) \Gamma \equiv \int_{t-\bar{D}}^{t} p(v, t) \mu(t-v) A(v, t) d v .
$$

Figure 9 visualizes the impact of the annuity market imperfection on labour supply and financial assets (As in the full model with transfers, consumption is hump shaped.). Figure 9(b) shows that assets accumulation is increased slightly for younger agents and reduced substantially for older agents. Furthermore, as in the core model and the first extension we find that agents retire early. Although similar to the calibration results in the other models, we find that draining the profits from the system leads to more pronounced results. That is, the income effect arising from the annuity market imperfection is substantial. This is especially visible when considering the growth rate, which drops by 39 basis points-see Table 2(d), column (ii).

\section{Conclusions}

Although prominently present in economic theory, annuity markets are notoriously imperfect in real life. In this paper we study the implications of an imperfect annuity market on, espe- 
cially, labour market decisions of individual agents and the general equilibrium repercussions on, and of, economic growth. In contrast to Conesa and Krueger (2006) and Conesa et al. (2009) we focus on an imperfect but not absent annuity market. This novel feature allows us to consider the impact of different degrees of imperfection. Furthermore, in contrast to Pecchenino and Pollard (1997), we explicitly focus on the labour market consequences of imperfect annuities. By studying endogenous intensive and extensive labour market decisions we can focus on the key channels by which imperfect annuities affect individual and aggregate outcomes.

We model an imperfect annuity market by setting the interest rate on life-insured loans and deposits below the actuarially fair rate. This assures that life-insurance firms make excess profits which have to be redistributed somehow. We then embed the imperfect annuity in a core model featuring overlapping generations and endogenous growth. The core model features age-independent wages and a constant mortality rate. Furthermore, we consider the implications of a realistic individual productivity profile and of a realistic mortality profile. We show that both extensions are needed to obtain a realistic calibration of the model.

The main findings emerging from our quantitative analysis are as follows. First, the way in which excess profits (arising from overpriced annuities) are redistributed has a large effect on the quantitative results. If these profits are handed back to the agents in a lump-sum fashion, then the annuity market imperfection only has rather modest effects on labour market entry, retirement, and macroeconomic growth. In contrast, if these profits are consumed by the government on useless activities, then the effects are much larger. Labour market entry and retirement both occur earlier in life, and the aggregate growth rate is reduced substantially as a result of the annuity imperfection.

Second, the core model substantially overstates the retirement and growth effects of the annuity imperfection. This is because its assumed demographic process "kills off" the young agents too quickly and the older agents not quickly enough. Optimizing macroeconomic models must include a realistic demographic process for these models to be of any quantitative use.

A rather robust finding from all model variants considered is that economic growth is lower under imperfect annuities than with perfect annuities. This findings begs the question whether there is role for a policy maker to mitigate the negative consequences of an imperfect 
annuity market. A natural candidate for such a policy is a public pension system. We aim to study this and other issues in future work. 


\section{References}

Abel, A. B. (1985). Precautionary saving and accidental bequests. American Economic Review, 75:777-791.

Blanchard, O.-J. (1985). Debts, deficits, and finite horizons. Journal of Political Economy, 93:223-247.

Boucekkine, R., de la Croix, D., and Licandro, O. (2002). Vintage human capital, demographic trends, and endogenous growth. Journal of Economic Theory, 104:340-375.

Buiter, W. H. (1988). Death, birth, productivity growth and debt neutrality. Economic Journal, 98:279-293.

Bütler, M. (2001). Neoclassical life-cycle consumption: A textbook example. Economic Theory, 17:209-221.

Cannon, E. and Tonks, I. (2008). Annuity Markets. Oxford University Press, Oxford.

Conesa, J. C., Kitao, S., and Krueger, D. (2009). Taxing capital? Not a bad idea after all! American Economic Review, 99:25-48.

Conesa, J. C. and Krueger, D. (2006). On the optimal progressivity of the income tax code. Journal of Monetary Economics, 53:1425-1450.

d'Albis, H. (2007). Demographic structure and capital accumulation. Journal of Economic Theory, 132:411-434.

Eckstein, Z., Eichenbaum, M., and Peled, D. (1985). Uncertain lifetimes and the welfare enhancing properties of annuity markets and social security. Journal of Public Economics, 26(3):303-326.

Eichenbaum, M. S. and Peled, D. (1987). Capital accumulation and annuities in an adverse selection economy. Journal of Political Economy, 95(2):334-54.

Fernandez-Villaverde, J. and Krueger, D. (2007). Consumption over the life cycle: Facts from consumer expenditure survey data. Review of Economics and Statistics, 89:552-565. 
Finkelstein, A. and Poterba, J. (2002). Selection effects in the United Kingdom individual annuities market. Economic Journal, 112(476):28-50.

Finkelstein, A. and Poterba, J. (2004). Adverse selection in insurance markets: Policyholder evidence from the U.K. annuity market. Journal of Political Economy, 112(1):183-208.

Finkelstein, A. and Poterba, J. (2006). Testing for adverse selection with "unused observables". Working Paper 12112, NBER, Cambridge, MA.

Fuster, L. (1999). Effects of uncertain lifetime and annuity insurance on capital accumulation and growth. Economic Theory, 13:429-445.

Gourinchas, P.-O. and Parker, J. A. (2002). Consumption over the life cycle. Econometrica, 70:47-89.

Hansen, G. D. (1993). The cyclical and secular behaviour of the labour input: Comparing efficiency units and hours worked. Journal of Applied Econometrics, 8:71-80.

Hansen, G. D. and İmrohoroğlu, S. (2008). Consumption over the life cycle: The role of annuities. Review of Economic Dynamics, 11:566-583.

Heijdra, B. J. and Mierau, J. O. (2009a). Annuity market imperfection, retirement and economic growth: Mathematical appendix. University of Groningen, May.

Heijdra, B. J. and Mierau, J. O. (2009b). Retirement and economic growth with uninsurable mortality risk. University of Groningen, July.

Heijdra, B. J. and Romp, W. E. (2008). A life-cycle overlapping-generations model of the small open economy. Oxford Economic Papers, 60:89-122.

Heijdra, B. J. and Romp, W. E. (2009a). Human capital formation and macroeconomic performance in an ageing small open economy. Journal of Economic Dynamics and Control, 33:725-744.

Heijdra, B. J. and Romp, W. E. (2009b). Retirement, pensions, and ageing. Journal of Public Economics, 93:586-604.

Huggett, M. (1996). Wealth distribution in life-cycle economies. Journal of Monetary Economics, 38:469-494. 
Hurd, M. D. (1989). Mortality risk and bequests. Econometrica, 57:779-813.

Leung, S. F. (1994). Uncertain lifetime, the theory of the consumer, and the life cycle hypothesis. Econometrica, 62:1233-1239.

Leung, S. F. (2007). The existence, uniqueness, and optimality of the terminal wealth depletion time in life-cycle models of saving under uncertain lifetime and borrowing constraint. Journal of Economic Theory, 134:470-493.

McGrattan, E. R. and Rogerson, R. (2004). Changes in hours worked, 1950-2000. Federal Reserve Bank of Minneapolis Quarterly Review, 28:14-33.

Pecchenino, R. A. and Pollard, P. S. (1997). The effects of annuities, bequests, and aging in an overlapping generations model with endogenous growth. Economic Journal, 107:26-46.

Ríos-Rull, J. V. (1996). Life-cycle economies and aggregate fluctuations. Review of Economic Studies, 63:465-489.

Romer, P. M. (1989). Capital accumulation in the theory of long-run growth. In Barro, R. J., editor, Modern Business Cycle Theory, pages 51-127. Basil Blackwell, Oxford.

Saint-Paul, G. (1992). Fiscal policy in an endogenous growth model. Quarterly Journal of Economics, 107:1243-1259.

Yaari, M. E. (1965). Uncertain lifetime, life insurance, and the theory of the consumer. Review of Economic Studies, 32:137-150. 


\section{CESifo Working Paper Series}

for full list see www.cesifo-group.org/wp

(address: Poschingerstr. 5, 81679 Munich, Germany, office@cesifo.de)

2653 Assaf Razin and Edith Sand, Migration-Regime Liberalization and Social Security: Political-Economy Effect, May 2009

2654 Yin-Wong Cheung and Hiro Ito, A Cross-Country Empirical Analysis of International Reserves, May 2009

2655 Bart Cockx and Bruno Van der Linden, Flexicurity in Belgium. A Proposal Based on Economic Principles, May 2009

2656 Michael Melvin, Lukas Menkhoff and Maik Schmeling, Exchange Rate Management in Emerging Markets: Intervention via an Electronic Limit Order Book, May 2009

2657 Susanne Neckermann, Reto Cueni and Bruno S. Frey, What is an Award Worth? An Econometric Assessment of the Impact of Awards on Employee Performance, May 2009

2658 Steven Brakman, Harry Garretsen and Charles van Marrewijk, Economic Geography within and between European Nations: The Role of Market Potential and Density across Space and Time, May 2009

2659 Giovanni Facchini and Cecilia Testa, Reforming Legislatures: Is one House better than two?, May 2009

2660 Carsten Kowalczyk and Raymond Riezman, Trade Agreements, May 2009

2661 Oliver Falck, Stephan Heblich and Elke Luedemann, Identity and Entrepreneurship, May 2009

2662 Christian Lessmann and Gunther Markwardt, One Size Fits All? Decentralization, Corruption, and the Monitoring of Bureaucrats, May 2009

2663 Felix Bierbrauer, On the Legitimacy of Coercion for the Financing of Public Goods, May 2009

2664 Alessandro Cigno, Agency in Family Policy: A Survey, May 2009

2665 Claudia M. Buch and Christian Pierdzioch, Low Skill but High Volatility?, May 2009

2666 Hendrik Jürges, Kerstin Schneider, Martin Senkbeil and Claus H. Carstensen, Assessment Drives Learning: The Effect of Central Exit Exams on Curricular Knowledge and Mathematical Literacy, June 2009

2667 Eric A. Hanushek and Ludger Woessmann, Schooling, Cognitive Skills, and the Latin American Growth Puzzle, June 2009 
2668 Ourania Karakosta, Christos Kotsogiannis and Miguel-Angel Lopez-Garcia, Does Indirect Tax Harmonization Deliver Pareto Improvements in the Presence of Global Public Goods?, June 2009

2669 Aleksandra Riedl and Silvia Rocha-Akis, Testing the Tax Competition Theory: How Elastic are National Tax Bases in OECD Countries?, June 2009

2670 Dominique Demougin and Carsten Helm, Incentive Contracts and Efficient Unemployment Benefits, June 2009

2671 Guglielmo Maria Caporale and Luis A. Gil-Alana, Long Memory in US Real Output per Capita, June 2009

2672 Jim Malley and Ulrich Woitek, Productivity Shocks and Aggregate Cycles in an Estimated Endogenous Growth Model, June 2009

2673 Vivek Ghosal, Business Strategy and Firm Reorganization under Changing Market Conditions, June 2009

2674 Francesco Menoncin and Paolo M. Panteghini, Retrospective Capital Gains Taxation in the Real World, June 2009

2675 Thomas Hemmelgarn and Gaëtan Nicodème, Tax Co-ordination in Europe: Assessing the First Years of the EU-Savings Taxation Directive, June 2009

2676 Oliver Himmler, The Effects of School Competition on Academic Achievement and Grading Standards, June 2009

2677 Rolf Golombek and Michael Hoel, International Cooperation on Climate-Friendly Technologies, June 2009

2678 Martin Cave and Matthew Corkery, Regulation and Barriers to Trade in Telecommunications Services in the European Union, June 2009

2679 Costas Arkolakis, A Unified Theory of Firm Selection and Growth, June 2009

2680 Michelle R. Garfinkel, Stergios Skaperdas and Constantinos Syropoulos, International Trade and Transnational Insecurity: How Comparative Advantage and Power are Jointly Determined, June 2009

2681 Marcelo Resende, Capital Structure and Regulation in U.S. Local Telephony: An Exploratory Econometric Study; June 2009

2682 Marc Gronwald and Janina Ketterer, Evaluating Emission Trading as a Policy Tool Evidence from Conditional Jump Models, June 2009

2683 Stephan O. Hornig, Horst Rottmann and Rüdiger Wapler, Information Asymmetry, Education Signals and the Case of Ethnic and Native Germans, June 2009 
2684 Benoit Dostie and Rajshri Jayaraman, The Effect of Adversity on Process Innovations and Managerial Incentives, June 2009

2685 Peter Egger, Christian Keuschnigg and Hannes Winner, Incorporation and Taxation: Theory and Firm-level Evidence, June 2009

2686 Chrysovalantou Milliou and Emmanuel Petrakis, Timing of Technology Adoption and Product Market Competition, June 2009

2687 Hans Degryse, Frank de Jong and Jérémie Lefebvre, An Empirical Analysis of Legal Insider Trading in the Netherlands, June 2009

2688 Subhasish M. Chowdhury, Dan Kovenock and Roman M. Sheremeta, An Experimental Investigation of Colonel Blotto Games, June 2009

2689 Alexander Chudik, M. Hashem Pesaran and Elisa Tosetti, Weak and Strong Cross Section Dependence and Estimation of Large Panels, June 2009

2690 Mohamed El Hedi Arouri and Christophe Rault, On the Influence of Oil Prices on Stock Markets: Evidence from Panel Analysis in GCC Countries, June 2009

2691 Lars P. Feld and Christoph A. Schaltegger, Political Stability and Fiscal Policy - Time Series Evidence for the Swiss Federal Level since 1849, June 2009

2692 Michael Funke and Marc Gronwald, A Convex Hull Approach to Counterfactual Analysis of Trade Openness and Growth, June 2009

2693 Patricia Funk and Christina Gathmann, Does Direct Democracy Reduce the Size of Government? New Evidence from Historical Data, 1890-2000, June 2009

2694 Kirsten Wandschneider and Nikolaus Wolf, Shooting on a Moving Target: Explaining European Bank Rates during the Interwar Period, June 2009

2695 J. Atsu Amegashie, Third-Party Intervention in Conflicts and the Indirect Samaritan's Dilemma, June 2009

2696 Enrico Spolaore and Romain Wacziarg, War and Relatedness, June 2009

2697 Steven Brakman, Charles van Marrewijk and Arjen van Witteloostuijn, Market Liberalization in the European Natural Gas Market - the Importance of Capacity Constraints and Efficiency Differences, July 2009

2698 Huifang Tian, John Whalley and Yuezhou Cai, Trade Sanctions, Financial Transfers and BRIC's Participation in Global Climate Change Negotiations, July 2009

2699 Axel Dreher and Justina A. V. Fischer, Government Decentralization as a Disincentive for Transnational Terror? An Empirical Analysis, July 2009

2700 Balázs Égert, Tomasz Koźluk and Douglas Sutherland, Infrastructure and Growth: Empirical Evidence, July 2009 
2701 Felix Bierbrauer, Optimal Income Taxation and Public Goods Provision in a Large Economy with Aggregate Uncertainty, July 2009

2702 Marc Gronwald, Investigating the U.S. Oil-Macroeconomy Nexus using Rolling Impulse Responses, July 2009

2703 Ali Bayar and Bram Smeets, Government Deficits in the European Union: An Analysis of Entry and Exit Dynamics, July 2009

2704 Stergios Skaperdas, The Costs of Organized Violence: A Review of the Evidence, July 2009

2705 António Afonso and Christophe Rault, Spend-and-tax: A Panel Data Investigation for the EU, July 2009

2706 Bruno S. Frey, Punishment - and beyond, July 2009

2707 Michael Melvin and Mark P. Taylor, The Crisis in the Foreign Exchange Market, July 2009

2708 Firouz Gahvari, Friedman Rule in a Model with Endogenous Growth and Cash-inadvance Constraint, July 2009

2709 Jon H. Fiva and Gisle James Natvik, Do Re-election Probabilities Influence Public Investment?, July 2009

2710 Jarko Fidrmuc and Iikka Korhonen, The Impact of the Global Financial Crisis on Business Cycles in Asian Emerging Economies, July 2009

2711 J. Atsu Amegashie, Incomplete Property Rights and Overinvestment, July 2009

2712 Frank R. Lichtenberg, Response to Baker and Fugh-Berman's Critique of my Paper, "Why has Longevity Increased more in some States than in others?", July 2009

2713 Hans Jarle Kind, Tore Nilssen and Lars Sørgard, Business Models for Media Firms: Does Competition Matter for how they Raise Revenue?, July 2009

2714 Beatrix Brügger, Rafael Lalive and Josef Zweimüller, Does Culture Affect Unemployment? Evidence from the Röstigraben, July 2009

2715 Oliver Falck, Michael Fritsch and Stephan Heblich, Bohemians, Human Capital, and Regional Economic Growth, July 2009

2716 Wladimir Raymond, Pierre Mohnen, Franz Palm and Sybrand Schim van der Loeff, Innovative Sales, R\&D and Total Innovation Expenditures: Panel Evidence on their Dynamics, July 2009

2717 Ben J. Heijdra and Jochen O. Mierau, Annuity Market Imperfection, Retirement and Economic Growth, July 2009 